\title{
Appropriate lung management in patients with primary antibody deficiencies
}

\section{Francesco Cinetto, Riccardo Scarpa, Federica Pulvirenti, Isabella Quinti, Carlo Agostini \& Cinzia Milito}

To cite this article: Francesco Cinetto, Riccardo Scarpa, Federica Pulvirenti, Isabella Quinti, Carlo Agostini \& Cinzia Milito (2019) Appropriate lung management in patients with primary antibody deficiencies, Expert Review of Respiratory Medicine, 13:9, 823-838, DOI: 10.1080/17476348.2019.1641085

To link to this article: https://doi.org/10.1080/17476348.2019.1641085

曲 Published online: 30 Jul 2019.

Submit your article to this journal $\pi$

III Article views: 32

Q View related articles $₫$

View Crossmark data $[\pi$ 


\title{
Appropriate lung management in patients with primary antibody deficiencies
}

\author{
Francesco Cinetto ${ }^{a, b}$, Riccardo Scarpa ${ }^{a, b}$, Federica Pulvirentic, Isabella Quintic, Carlo Agostini ${ }^{a, b}$ and Cinzia Milito ${ }^{c}$ \\ aDepartment of Medicine - DIMED, University of Padova, Padova, Italy; 'Internal Medicine I, Ca' Foncello Hospital, Treviso, Italy; 'Department of \\ Molecular Medicine, "Sapienza" University of Roma, Roma, Italy
}

\begin{abstract}
Introduction: Human primary immunodeficiency diseases (PIDs) include a broad spectrum of more than 350 disorders, involving different branches of the immune system and classified as 'rare diseases.' Predominantly antibody deficiencies (PADs) represent more than half of the PIDs diagnosed in Europe and are often diagnosed in the adulthood.

Areas covered: Although PAD could first present with autoimmune or neoplastic features, respiratory infections are frequent and respiratory disease represents a relevant cause of morbidity and mortality. Pulmonary complications may be classified as infection-related (acute and chronic), immune-mediated, and neoplastic.

Expert opinion: At present, no consensus guidelines are available on how to monitor and manage lung complications in PAD patients. In this review, we will discuss the available diagnostic, prognostic and therapeutic instruments and we will suggest an appropriate and evidence-based approach to lung diseases in primary antibody deficiencies. We will also highlight the possible role of promising new tools and strategies in the management of pulmonary complications. However, future studies are needed to reduce of diagnostic delay of PAD and to better understand lung diseases mechanisms, with the final aim to ameliorate therapeutic options that will have a strong impact on Quality of Life and long-term prognosis of PAD patients.
\end{abstract}

ARTICLE HISTORY

Received 19 April 2019

Accepted 4 July 2019

KEYWORDS

Primary antibody

deficiencies; GLILD; CVID;

bronchiectasis; lung MRI

\section{Introduction}

Human primary immunodeficiency diseases (PIDs) include a broad spectrum of disorders (more than 350 according to the International Union of Immunological Societies - IUIS classification), involving different branches of the immune system [1]. Most of them are defined by a well-known underlying genetic defect [1,2]. PIDs are known as 'rare diseases,' but their global incidence might be much more relevant than what generally thought [3]. It has been estimated that something around 6 million people worldwide might be affected by a PID, no more than $1 \%$ of which having been definitely diagnosed [4]. The immunologic defect may be broad or extremely selective/specific, implying a huge heterogeneity in infectious manifestations, both in terms of severity and range of involved pathogens [1]. Moreover, infections might not be the main features of certain PIDs (e.g. hereditary angioedema, IPEX or auto-inflammatory disorders). Indeed, the first clinical presentation of some PIDs may be an autoimmune disease or cancer [5,6]. This variability gives a reason for the high degree of underdiagnosis or diagnostic delay.

Despite representing a small number of the IUIS-recognized diseases, predominantly antibody deficiencies (PADs) represent more than a half of the PIDs diagnosed in Europe, according to the ESID registry, and the percentage increases if we consider adult patients [7]. Either B cell intrinsic or B cell extrinsic defects may lead to the impairment in antibody production, but the genetic and mechanistic etiologies are still unknown for the majority of patients. The most prevalent symptomatic PAD, indeed, Common Variable Immunodeficiency (CVID), is characterized by a variable phenotype whose genetic basis is still under investigation [8].

Compared to cellular or combined immunodeficiencies, defects of the humoral immune response tend to have a better long-term prognosis and are often diagnosed in the adulthood, with a peak around the third decade of life [9]. A recent paper based on ESID registry reported a median age at diagnosis of 31 and a mean of 31.4 years for CVID [10]. Respiratory disease is a relevant cause of morbidity and mortality in PAD patients [11]. Pulmonary complications may be classified as infection-related (acute and chronic), immunemediated and neoplastic [12]. Respiratory tract infections (RTI) need an immediate and appropriate diagnostic approach. Due to recurrence, underlying immune defects, diagnostic delay, and not always appropriate management, infections may lead to long-term consequences on airways architecture and function, inducing bronchiectasis, COPD and poor asthma control. Immune-mediated complications encompass a range of interstitial lung diseases (ILDs), that might all be part of a specific entity called GLILD (Granulomatous-Lymphocytic Interstitial Lung Disease). Finally, malignancies are a major cause of morbidity and mortality in PAD and may involve the respiratory tract $[5,6,11,13]$.

No worldwide accepted or European consensus guidelines are currently available on how to monitor and manage lung complications in PID patients. A recent survey, indeed, showed 


\section{Article highlights}

- Internationally recognized evidence-based guidelines need to be designed, in order to standardize the approach to diagnosis, monitoring, and treatment of lung diseases in PAD. This will go through technical improvements and new acquisitions in terms of pathogenic mechanisms and will reduce the diagnostic delay of lung complications, improving patients' QoL and survival.

- IgG replacement therapy enhances survival and reduces severe and invasive infections. However, patients might still develop chronic infection-related lung disease (CLD). Adjunct therapies as Azithromycin prophylaxis, pulmonary rehabilitation, and new $\lg A$ and IgM enriched Ig preparations that will soon be available need to be included in standardized guidelines, in order to prevent the progression of CLD.

- HRCT scan still represents the gold standard for lung imaging in PADs. Recent evidence supports the possible role of lung magnetic resonance imaging (MRI) in diagnosing and monitoring lung disease in PAD patients. Without exposure to ionizing radiation, recently developed chest MRI techniques might offer both structural and functional information in a single examination. MRI is thus destined to become a routinely used lung imaging approach for PAD patients.

- GLILD, whose diagnosis is currently based on a multi-step process culminating in an invasive open-lung or VATS biopsy, still represents a great challenge. In the next future, the diagnostic process will hopefully move to a more clinical-radiologic-plus-MDT-discussion-based approach, with an increasing importance of BAL. Cryo-biopsy will likely become the first-line approach when a lung tissue biopsy is needed.

- In terms of treatment, we are looking for interesting correlations between GLILD behavior and possible predisposing factors, underlying genetic defects, concomitant conditions, peripheral blood or BALF lymphocytes distribution, histochemical characterization of tissue samples. These correlations will emerge from ongoing observational studies and from case series, allowing clinicians to consider more tailored treatment strategies either on the basis of patients' classification in subgroups, or starting from the immunologic mechanisms highlighted in each single patient.

- Starting from a better understanding of mechanisms and correlations, relatively large multicenter-controlled trial with existing drugs will be designed, hopefully leading to PAD-specific evidence-based treatment guidelines for ILDs.

a great heterogeneity in the frequency of clinical, functional and radiologic evaluation of patients' lung health across Europe [14]. Herein we will discuss the available diagnostic, prognostic and therapeutic instruments and we will suggest an appropriate and evidence-based approach to lung diseases in primary antibody deficiencies. We will focus on those diseases listed between the 'predominantly antibody deficiency' in the IUIS classification, particularly referring to those in which IgG replacement represents the standard of therapy [1].

\section{Primary antibody deficiencies}

The spectrum of Primary Antibody Deficiencies ranges from conditions with Mendelian inheritance, as X-linked (XLA) or autosomal recessive Agammaglobulinemia, to diseases with predominant polygenic inheritance, such as Common Variable Immunodeficiency (CVID) [9]. Mature B cells may thus be absent, as in XLA, or may present an almost normal development, being selectively impaired only the antibody response to polysaccaridic antigens, as in Specific Antibody Deficiencies (SpAD). Inadequate response to micro-organisms goes together with a poor response to vaccination (e.g. 23valent anti-pneumococcal vaccine), that is indeed included between the diagnostic criteria for CVID [9].
Due to the lack of protective antibodies, the respiratory tract is the major target for acute infections, requiring immunoglobulin replacement therapy and frequent courses of antibiotics $[15,16]$. Recent studies underline that IgG replacement therapy enhances survival and reduces risk of pneumonia and other invasive infections [17], but substitutive therapy, even at high dose, cannot block the development of chronic infection-related pulmonary diseases $[18,19]$.

Apart from the infection-related symptoms, PAD may be characterized by an increased incidence of allergic and autoimmune diseases, polyclonal lymphoproliferation and cancer, due to an underlying immune dysregulation usually accompanying the immune defect [20-22].

\section{Pulmonary complications of PADs and their management}

\subsection{Infections and infection-related diseases}

PAD-associated acute infections (e.g. pneumonia) and chronic infection-related lung diseases (bronchiectasis, COPD) have been accurately described in several reviews and retrospective studies [12,23-25]. The defect in antibodymediated response explains the susceptibility to bacterial infections and their recurrence. The impaired response also influences the time to complete recovery despite appropriate treatment, the rate of colonization in the presence of bronchiectasis and the degree of resistance following the repeated use of antibiotics [25]. Selective $\lg A$ deficiency (slgAD) may be asymptomatic or mildly symptomatic in terms of infections, that mainly involve the respiratory tract [26]. The co-existence of an IgG subclass deficiency may significantly worsen the infectious phenotype [27]. IgG deficiency is characterized by recurrent sinopulmonary infections, with rates of sinusitis and pneumonia similar to CVID; CVID patients, however, present a significantly higher prevalence of bronchiectasis and of non-infectious complications [28]. Moreover, diseases as congenital agammaglobulinemia and hyper-IgM syndromes (HIgM) (when due to a defective CD40:CD40 ligand interaction), may present a deeper immune defect if compared to other PADs, leading to a more severe infectious phenotype with increased susceptibility, respectively, to certain viral infections or to opportunistic infections like Pneumocystis Jirovecii [29,30]. More in general, it has been suggested that in PADs the impairment in immune response might be broader than what commonly thought, involving multiple non-B cell immunological defects, such as T-cell, MBL, TLR, AMP deficiency, and/or impaired neutrophil function [31]. Recent studies, indeed, highlighted the increased frequency of viral infections and viral-plus-bacterial co-infections in PAD patients, particularly during symptomatic respiratory exacerbations [25,32]. This might explain why, in agammaglobulinemic as in some CVID patients, chronic lung disease progression still occurs despite maintaining an appropriate IgG trough level, with a rate of decline in lung function that is approximately twofold in CVID patients compared to the rate of healthy non-smoking adults [24,33,34]. 


\subsubsection{Acute infections}

To promptly manage acute pulmonary infections in PAD patients, early imaging (computed tomography [CT] scan) and specific microbiologic sampling represent the optimal approach. The latter may require non-invasive tests (e.g sputum culture), but invasive procedures (e.g. bronchoscopy to reveal bacterial grown in bronchoalveolar lavage fluid, lung biopsies in case of solid/cavitary lesions) are often necessary to obtain a representative sample. Once the microbiologic diagnosis is established, an antimicrobial susceptibility test will determine the drug of choice. Sometimes advanced diagnostic testing including immunohistochemistry and quantitative molecular assays may be performed as additional components in the diagnostic algorithm [35,36].

The importance of early antimicrobial therapy cannot be overemphasized, accordingly broad-spectrum antimicrobial therapy must be started as soon as possible, considering patients' epidemiologic history and any prior microbiologic data or previous courses of antimicrobial agents. A list of the most involved pathogens is reported in Table 1 . Once the microbiologic diagnosis is made, empiric therapy can be modified accordingly. The optimal duration of antimicrobial treatment of PAD patients has not been defined, even if is generally accepted the need for longer courses if compared to immunocompetent individuals. Experienced clinicians often prescribe courses of antimicrobials that are at least two times longer than standard recommendations.

Furthermore, to provide adequate Ig replacement therapy is essential in this context. As no specific lgG trough concentration has been defined, target lgG trough level should be the one able to keep the patient infection-free [24]. Therefore, transiently, higher doses of $\mathrm{lg}(600-800 \mathrm{mg} / \mathrm{kg} / \mathrm{month})$ may help to clear acute bacterial infections and possibly to prevent the evolution towards chronic lung disease $[45,46]$.

\subsubsection{Chronic infection-related airways diseases}

The cumulative incidence of chronic lung diseases has been decribed to reach $80 \%$ after a 17 -year follow-up in a cohort of XLA patients [47] while in CVID, the incidence of bronchiectasis has been shown to increase over time for almost all age groups, leading to an increased risk of death $[24,25,48]$. More generally, a recently published study showed radiological evidence of bronchial pathology (bronchiectasis in $61 \%$, bronchial wall thickening in $44 \%$ and mucus plugging in $29 \%$ ) in $80 \%$ of chest HRCT scan of a multicenter cohort of CVID patients [49]. Chronic infection-related lung damage (e.g. bronchiectasis) has not been reported as a significant feature of slgAD $[26,50]$. The co-existence of an IgG subclass deficiency has been shown to be crucial in terms of chronicity and severity of lung disease [27]. The high incidence of chronic lung diseases is a direct consequence of diagnostic delay, severity of the infectious respiratory phenotype, and difficulty to define appropriate treatment strategies. The recurrence of acute infections over these underlying chronic lung conditions has been proposed to be defined as respiratory exacerbations of PAD patients, using the definition already validated for COPD [25]. Respiratory exacerbations in PAD are mainly caused by encapsulated bacteria. Despite an appropriate IgG replacement therapy, indeed, low IgM and particularly low $\lg A$ serum levels have been found to be risk factors for $\mathrm{S}$. pneumoniae and $\mathrm{H}$. influenzae airways colonization [51]. Chronic lung disease (CLD) is a relevant cause of mortality in PAD patients. In a cohort of XLA patients, after 25 years of follow-up, 38\% of deaths were due to CLD. In an Italian cohort of CVID patient, death for respiratory failure due to chronic lung disease accounted for $30.4 \%$ of all causes of death $[6,47]$.

3.1.2.1. Bronchiectasis. The most prevalent chronic infectionrelated lung disease diagnosed in PADs is bronchiectasis [10,34]. Other chronic pulmonary complications affecting airways include chronic obstructive pulmonary disease (COPD) and asthma [31,52]. Bronchiectasis present as atypical bronchial and bronchiolar dilatations, resulting from a 'vicious cycle,' in which repeated episodes of infection and inflammation lead to the destruction of the airways and lung parenchyma, with a consequent decline in lung function [31,53-55] (Figure 1). A recent retrospective study on adult patients with primary antibody deficiencies reported $47 \%$ suffering from bronchiectasis; history of LRTI was the only factor directly associated with the development of bronchiectasis $[19,56]$. However, it has also been demonstrated that, once the remodeling process is ongoing, airway inflammation gets worse even in the absence of bacterial infection. This is related to neutrophil accumulation through an increase in pro-inflammatory cytokines expression and adhesion molecule production. Over time, airway inflammation leads to hyper-reactivity, further lung remodeling, and development of new bronchiectasis [57,58]. In PAD patients, defects and dysregulation of the immune system further enhance this vicious cycle [31].

3.1.2.2 Management. The management of bronchiectasis has been extensively studied in cystic fibrosis (CF) patients. On the contrary, there is no standardized treatment for adult non-cystic fibrosis bronchiectasis (NCFB), including those related to PIDs, and therapeutic strategies tend to be simply extrapolated from CF clinical trials [59]. Several clinical trials

Table 1. Infectious pathogens reported in respiratory tract infections (RTI) in PADs.

\begin{tabular}{|c|c|c|}
\hline Type of pathogen & Isolated pathogen & Reference \\
\hline Bacteria & $\begin{array}{l}\text { Frequent: Haemophilus influenzae type B, Streptococcus pneumoniae, Pseudomonas spp, Staphylococcus spp. } \\
\text { (incl. Methicillin resistant), Mycoplasma spp, Neisseria meningitidis, Moraxella spp. } \\
\text { Rare: Klebsiella spp, Bordetella pertussis, Chlamydia trachomatis, Ureaplasma urealyticum, Fusobacteriumspp, } \\
\text { Serratia spp, Stenotrophomonas maltophilia, Enterobacterspp, Proteus spp, Achromobacter xylosoxidans, } \\
\text { Citrobacter spp. }\end{array}$ & {$[25,31,32,37-40,92]$} \\
\hline Virus & Rhinovirus, Adenovirus, Coronavirus, Influenza A, Influenza B, enterovirus, RSV, hMPV & {$[31,41,42]$} \\
\hline $\begin{array}{l}\text { Opportunistic pathogens } \\
\text { (rare, reported in XLA } \\
\text { and HIGM) }\end{array}$ & Mycobacterium hominis, Mycobacterium avium, Pneumocystis Jirovecii & {$[29,31,40,43,44,92]$} \\
\hline
\end{tabular}




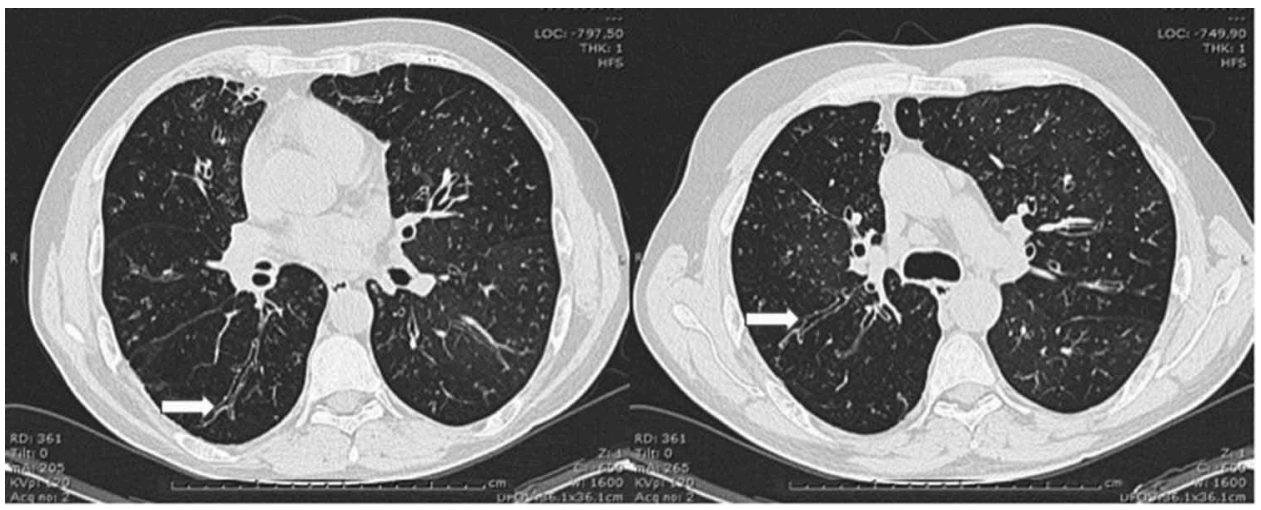

Figure 1. Bronchiectasis in a CVID patient. Panels show bronchiectasis (arrows) in a CVID patient in two different slices of a chest high-resolution CT scan.

have proven that macrolide antibiotics are effective to successfully manage cystic fibrosis (CF), non-CF associated bronchiectasis (NCFB), COPD, and asthma [60-64] all conditions with a lower rate of respiratory exacerbations in comparison to severe PAD. Macrolides, especially azithromycin, have antimicrobial, immunomodulatory and anti-inflammatory properties, and prevent the development of the biofilm produced by bacteria, acting on the vicious circle infectioninflammation that leads to airway hyper-reactivity and remodeling [57]. Differently from these respiratory diseases, no guidelines to manage respiratory diseases in PAD patients are available. Despite lacking specific evidence, physiotherapy programs and antibiotic prophylaxis have been routinely used in PAD patients with bronchiectasis [65-67]. Only few reviews have been written on the use of antimicrobial prophylaxis in PAD. According to these papers, the efficacy of antimicrobial prophylaxis in PADs patients remains uncertain and the risk of bacterial resistance makes this practice poorly widespread. However, PAD patients might take advantage of antibiotics prophylaxis [8]. Up to now the use of antibiotic prophylaxis in CVID has been heterogeneous and mainly based on singleinstitution-specific experience [68]. There has been no consensus on which antibiotic agent to use, at what dose (half of a therapeutic dose, full doses) and on how to schedule the prophylactic regimen (intermittent single agent, rotational antibiotics, periodically changing antibiotics monthly to every 6 months). Moreover, the available reports were neither based on randomized clinical trial, nor associated with controlled measurements of patients safety and quality health outcomes [69]. Recently, new data on antibiotic prophylaxis in PAD patients became available from a 36-month, Phase II, randomized, double-blind, placebo-controlled, multi-center clinical trial on long-term prophylactic treatment with azithromycin in adult PAD patients [70]. In that trial, 89 PAD patients with bronchiectasis and/or COPD were enrolled. Patients received for 24 months either azithromycin, $250 \mathrm{mg}$ once daily for three consecutive days per week, or an identicalappearing placebo. The study showed that long-term oral azithromycin prophylaxis in patients affected by primary antibody deficiencies and chronic infection-related pulmonary diseases significantly reduced the episodes of respiratory exacerbations per patient-year. Moreover, in the group of patients receiving azithromycin, the number of additional courses of antibiotics for treating respiratory exacerbations was lower than in the placebo group, as well as the number of hospitalizations. In addition, after starting azithromycin, decreased counts of absolute number of WBC and neutrophils were observed. The administration of azithromycin was proven to be safe as no serious adverse events or drug-related cardiovascular mortality were reported. It had been previously demonstrated that daily intake of low dose of azithromycin resulted in development of azithromycin-resistant pathogens, whereas the same dose given 3 times a week did not increase bacterial resistance [71]. During the study time, indeed, an increased rate of macrolide-resistant organisms was not observed in the azithromycin compared to the placebo group [70]. These results were comparable with those already provided by other similar randomized studies done in COPD, in CF patients and in non-CF patients with bronchiectasis, although a lower azithromycin dosage has been used [6064]. The efficacy of a low-dose macrolide prophylaxis on PAD respiratory exacerbations could be related both to antimicrobial and anti-inflammatory action of the macrolides and is confirmed by the decrease of neutrophils count [70].

Although an increased rate of macrolide-resistant organisms was not observed, physicians need to take into consideration the evidence that macrolides resistance is increasing $[72,73]$. However, the risk of driving a bacterial resistance because of long-term macrolide prophylaxis could be balanced by benefits on the overall bacterial resistance due to the reduction of number of antibiotic courses. In the trial, no sputum sample positive for non-tuberculous mycobacterial infection was identified. Despite that, clinicians have to take into account that azithromycin could also select resistant nontuberculous mycobacteria if mycobacterial infection is present, especially in presence of bronchiectasis, thus predisposing to non-tuberculous mycobacterial infection, in the same way as in CF [74]. As a consequence, pulmonary nontuberculous mycobacterial infection should be ruled out before starting long-term azithromycin prophylaxis [74]. On the basis of the above-mentioned evidence, however, adding azithromycin to the treatment regimen of PAD patients with chronic infectionrelated pulmonary diseases may be considered a good choice.

Apart from antibiotic prophylaxis, physiotherapy represents another standard adjunct to therapy in NCFB that is used in PAD patients with bronchiectasis and chronic lung disease, 
despite lacking consensus guidelines stating a precise indication and the best approach [75,76]. A supervised Pulmonary Rehabilitation and Exercise Training programs might be recommended to certain patients, even though a short-term improvement in exercise capacity and Heath-Related QoL, does not necessarily predict to a long-term benefit [77].

3.1.2.3. Asthma and COPD. Chronic airways inflammation due to recurrent infections may lead to airway hyper-reactivity and remodeling, with reversible or fixed obstruction. Indeed, an impaired antibody response has been suggested as a possible cause of COPD in those patients without smoking history and/or alpha-1 proteinase inhibitor deficiency [78]. An association between bronchial hyper-reactivity after methacholine challenge test and PADs has also been highlighted, particularly when an IgA deficiency is present [79]. PAD patients also present an increased frequency of allergic diseases. Thus, frequently exacerbating asthmatic and COPD patients are more likely to receive a diagnosis of PAD, particularly slgAD, SpAD, IgG subclass deficiency, and CVID $[80,81]$. This association may account for the increased frequency of bacterial infections driving acute exacerbations of the underlying respiratory disease and for the inadequate control despite optimal medical therapy $[81,82]$. All these considered, PADs should be ruled out in frequently exacerbating COPD and severe uncontrolled asthmatic patients, even if sometimes the distinction between primary and secondary antibody deficiency might be complicated $[78,83]$.

3.1.2.4 Management. The presence of bronchial hyperreactivity and fixed obstruction must be ruled out in PAD patients, performing a complete plethysmography and, when appropriate, a methacholine challenge. The standard medical therapy for asthma and COPD may be applied to PAD patients. Moreover, there is evidence of a positive impact of Ig replacement therapy on chronic obstructive lung diseases, leading to amelioration of airway obstruction and reduction in the frequency of exacerbations, particularly in asthmatic and COPD patients with previously undiagnosed PAD [84-86]. Azithromycin prophylaxis and pulmonary rehabilitation programs may also be helpful. The consequent reduction in courses and cumulative annual dose of oral corticosteroids, potentially further lowering the gamma-globulin serum levels, rescue antibiotic use, and hospitalizations for acute respiratory exacerbations of asthma and COPD may have a significant impact on QoL, development of antibiotic resistance and healthcare costs.

\subsection{Immune-mediated lung diseases}

Apart from infection-related complication, a great challenge in PAD patients' management is currently represented by the Interstitial Lung Diseases (ILDs). Despite a possible role of infectious agents as triggers having been hypothesized, the hallmark of ILDs is represented by immune dysregulation; the whole pathogenic mechanisms, however, are still far from being understood [87-90].

\subsubsection{Interstitial lung diseases}

As for immunocompetent patients, ILDs consist of a group of diseases relying on a chronic inflammatory and often pro-fibrotic process clinically characterized by the insidious onset of dry cough and dyspnoea on effort. Commonly, symptoms do not occur in the initial stages, and an unrecognized or lately recognized disease progression may lead to pulmonary fibrosis, possibly complicated by pulmonary hypertension, cor pulmonale, and progressive respiratory failure. In terms of lung function, a decrease in carbon monoxide diffusion capacity could precede the onset of a restrictive pattern at PFTs. Thus, a DLCO reduction should be investigated by additional dynamic functional testing, as 6-min walking test (6MWT) or Cardiopulmonary Exercise Test (CPET). Chest imaging (HRCT) modifications may also anticipate clinical and functional manifestations [91].

ILDs, rather than recurrent infections and bronchiectasis, have been suggested as the main cause of a decline in lung function in patients with CVID [11]. Moreover, the prevalence of ILDs in PAD patients with recurrent respiratory infections has been reported as much higher than expected in the general population $[11,92,93]$. A prevalence of at least $10-20 \%$ has been reported in CVID, but it is likely underestimated [94,95]. ILDs have also been reported in other PADs. Occasionally, they may be found in selective IgA deficiency, particularly when associated with IgG subclass deficiency and to a clinical phenotype dominated by autoimmune features [16]. More commonly, they have been described as a feature of CTLA-4 haploinsufficiency and STAT3 gain-of-funtion mutations [96,97]. Granulomatous or Lymphocytic ILDs have also been described in patients with a CVID phenotype and an underlying defect in recombinationactivating gene 1 (RAG1), and in lipopolysaccharide responsive beige-like anchor protein (LRBA) deficiency [98-101]. Finally, Granulomatous-lymphocytic ILD (GLILD) has been reported in at least two patients with 22q11.2 deletion syndrome [102]. On the other hand, there is no evidence of ILDs in different cohorts of HIGM syndrome and congenital agammaglobulinemia patients [16]. Thus, the diagnostic process of a primary antibody deficiency with ILD features should be completed with a genetic analysis, aimed at identifying defects as LRBA or CTLA-4 deficiencies that, for instance, belong to the group of 'diseases of immune dysregulation' of the IUIS classification of primary immunodeficiencies. In terms of severity, there are no data showing specific associations between ILD severity and the type of PAD.

Different ILD patterns have been described in PADs, including follicular bronchiolitis (FB), nodular lymphoid hyperplasia, sarcoid-like granulomatous disease, organizing pneumonia (OP), lymphocytic interstitial pneumonia (LIP), non-specific interstitial pneumonia (NSIP) and hypersensitivity pneumonitis (HP), with possible radiologic and histologic overlapping features [100,103-105]. There is no consistent correlation between specific ILD patterns and a particular immune deficiency [11]. Systemic immune-mediated disorders potentially affecting the lung interstitium may also be present in patients with primary antibody defects (e.g. vasculitis and connective tissue diseases) [92].

3.2.1.1. GLILD. More recently, the 'umbrella' definition of 'granulomatous lymphocytic interstitial lung disease' (GLILD) has been adopted, encompassing granulomatous disease and all forms of pulmonary lymphoid hyperplasia (PLH) found in PAD 
$[95,106]$. The exact borders of this definition may appear still not clear but, due to its broad spectrum of histologic and radiological patterns, it has been described as the most common ILD in PADs (Table 2). Thus, we will subsequently refer to GLILD as a spectrum of diseases rather than to a single, univocal disease.

According to the British Lung Foundation/UK-PID Network consensus statement, GLILD represents 'a distinct clinico-radio -pathological ILD occurring in patients with CVID, associated with a lymphocytic infiltrate and/or granuloma in the lung, and in whom other conditions have been considered and, where possible, excluded' [108]. GLILD has been associated with poor clinical outcomes. Its pathogenesis and appropriate management are currently under investigation [11,18,105]. Infectious agents may act as triggers, as hypothesized for other granulomatous diseases $[90,109]$. GLILD is usually described as part of a multisystem granulomatous/inflammatory disease, potentially involving lymph-nodes, spleen, liver, $\mathrm{Gl}$ tract and/or other organs $[108,110]$. The presence of splenomegaly, past or present immune cytopenias (ITP or AIHA), low serum lgA levels, higher lgM levels, and percentage expansion of CD21low $B$ cells have been suggested as highly sensitive predictors, allowing the identification of a subset of PAD patients with higher risk for developing GLILD [111,112].

The main histopathological features are represented by peri-bronchiolar and/or interstitial lymphocytic infiltration and sarcoid-like non-caseating granulomas. Features of organizing pneumonia and interstitial fibrosis may also be seen in a significant proportion of patients. The ectopic B cell follicles express markers of germinal centers and proliferation despite the underlying $B$ cell maturation defects [95]. T cells (particularly (D4+) have been described as the predominant lymphocyte population in most patients; $B$ cell tissue predominance is less frequent. Regulatory $\mathrm{T}$ cells (Treg) have been reported as almost absent [100,105].

Despite prognosis having been described as poor, no specific data are available regarding ILD-related mortality in PAD patients. It is likely that mortality due to chronic lung disease in PAD cohorts includes also ILD-related mortality, at least in those PADs known to be potentially complicated by ILDs [113]. What we know is mainly derived from CVID-based studies. In a single-center CVID cohort from Colorado, U.S., a significantly worse survival was found between GLILD and all other non-infectious lung complications [105]. Poorer survival in CVID has been associated with the prevalence of GLILD (and cancer) in a recent retrospective analysis of the European Society for Immunodeficiency (ESID) registry data, while the presence of granulomatous disease (including extrapulmonary location) has not been related to a significantly reduced survival in a U.S.-based cohort $[10,113]$.

3.2.1.2 Management. As for other ILDs, patients complaining dry cough or dyspnea, or showing signatures of ILD during the routine lung monitoring for PAD, should undergo pulmonary function tests to rule out the presence of a possible restrictive pattern, an impairment in gas transfer, hypoxia at rest or on exercise (during 6MWT or cardio-pulmonary exercise test (CPET)).

High-resolution computed tomography (HRCT), the gold standard imaging technique for ILDs, may show parenchymal consolidation, bronchial wall thickening, reticular and/or nodular changes and/or fibrosis, with or without ground-glass opacities, predominantly affecting the lower lobes (Figure 2(a-d)). Bronchiectasis, air trapping, emphysema may also be present, since GLILD does not necessarily occur as single lung signature of PAD $[114,115]$. No validated radiologic scores are currently available for GLILD. The differential diagnosis includes infections, other well-defined ILDs (particularly sarcoidosis) and monoclonal lymphoproliferative diseases. FDG-positron emission tomography-CT (PET-CT) may thus be performed when the initial suspicion is lymphoma, potentially unmasking a clinically hidden extra-pulmonary involvement. A recent study underlined the role of FDG-PET-CT scan also in assessing and monitoring the response to treatment in CVID patients with GLILD [116] (Figure 2(e)).

Definitive diagnosis, in PAD patients, relies on a high index of suspicion, on the basis of clinical, radiological and microbiological picture, and on histopathologic confirmation [100]. An open lung or VATS biopsy should be performed, if safe, in order to provide the Pathologist with an optimal sample. Before surgery, bronchoscopy is recommended to rule out a possible infectious explanation for the interstitial picture [108]. The role of Broncho-

Table 2. Main features of GLILD $[12,16,107,108,117]$

\begin{tabular}{|c|c|}
\hline Associated PADs & $\begin{array}{l}\text { CVID, SIgAD, and IgG subclass deficiency, CTLA-4 haploinsufficiency and STAT3 GOF mutations, RAG1 and LRBA) deficiency. No } \\
\text { evidence in HIGM syndrome and congenital agammaglobulinemia patients [12]. }\end{array}$ \\
\hline Peripheral B cells & Circulating switched-memory B cells may be reduced, while CD21/ow B cells are often increased [111]. \\
\hline BALF lymphocytes & $\begin{array}{l}\text { Lymphocytosis is frequent }(>20 \%) \text {; } C D 4 / C D 8 \text { ratio has been reported increased or normal in different case series. CD21/ow } \\
\text { B cells have been reported as the major B cell population in BALF [117-119]. }\end{array}$ \\
\hline Associated lung conditions & Frequent infections and possible coexistence of bronchiectasis, COPD and asthma. \\
\hline $\begin{array}{l}\text { Associated extra-pulmonary } \\
\text { conditions }\end{array}$ & $\begin{array}{l}\text { Autoimmune cytopenia and splenomegaly are frequently present, Gastrointestinal involvement is reported in } 15 \% \text { of cases; } \\
\text { there is an increased likelihood of nodular regenerative hyperplasia of the liver [117]. }\end{array}$ \\
\hline $\begin{array}{l}\text { Main non-infectious differential } \\
\text { diagnoses }\end{array}$ & Sarcoidosis, other ILDs, Malignant lymphoproliferative diseases, metastases or lung cancer \\
\hline Lung function & DLCO reduction, slowly progressing restrictive lung disease [108]. \\
\hline Main radiologic patterns & $\begin{array}{l}\text { Pulmonary lymphoid hyperplasia features (e.g. LIP, follicular bronchiolitis); NSIP; Organizing Pneumonia. Diffuse lung nodules, often } \\
>1 \mathrm{~cm} \text {, with random or predominantly basal distribution; ground-glass opacities; hilar adenopathy may be present [115,117]. }\end{array}$ \\
\hline Concomitant radiologic findings & Bronchiectasis, emphysema, post-infectious aspects \\
\hline Typical histologic findings & Pulmonary lymphoid hyperplasia features, organizing pneumonia, non-necrotizing granulomatous inflammation [100]. \\
\hline \multirow[t]{2}{*}{ Treatment } & No evidence-based guidelines [108]. \\
\hline & $\begin{array}{l}\text { Optimize IgG replacement therapy and consider watchful waiting if asymptomatic and no decline in lung function } \\
\text { If treatment is needed: } \\
\text { - Steroids as first line or induction treatment } \\
\text { - Azathioprine/Mycophenolate as steroid-sparing and/or Rituximab }\end{array}$ \\
\hline
\end{tabular}



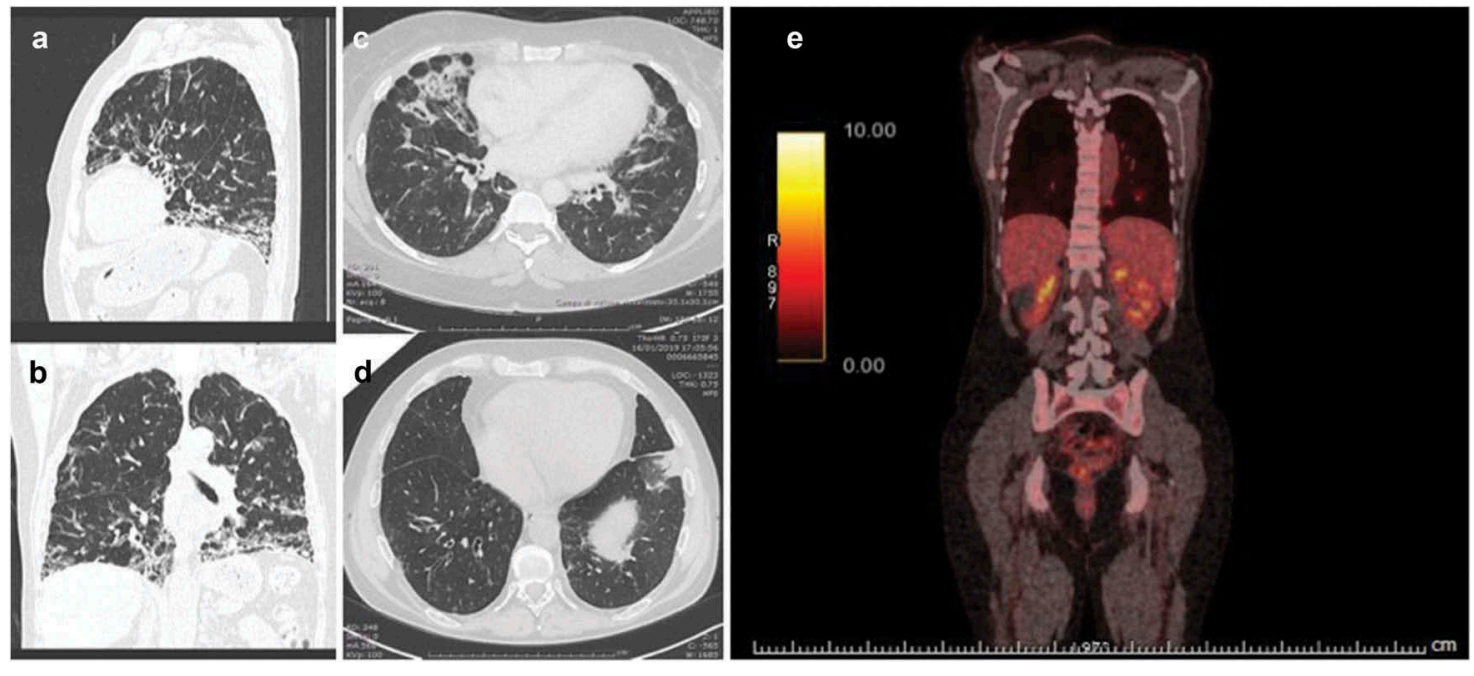

Figure 2. GLILD in CVID patients. Coronal (a) and sagittal (b) view of a CVID patient with a predominantly basal ILD with LIP-like radiological features. Different types of consolidations in CVID patients (c and d). Panel (d) shows an OP-like radiological pattern. All these patients received histologic diagnosis of GLILD. Panel (e) shows PET-CT scan of a 45 yo lady presenting GLILD in CVID; FDG uptake highlight mediastinal lymph-nodes, predominantly basal lung consolidations, liver, and spleen, with significant splenomegaly, bowel, and intraperitoneal lymph-nodes.

alveolar lavage fluid (BALF) cytology and flow-cytometric analysis, instead, is not yet defined. BALF has been described as lymphocyte-enriched (>20\%) in adult CVID patients affected by GLILD. An increased CD4/CD8 ratio of BALF lymphocytes has been reported, but not confirmed in other case series [117119]. CD21 low $B$ cells have also been suggested as the dominant cells in the BALF of patients diagnosed with GLILD [109]. It has been hypothesized that different BALF lymphocytes distributions might imply distinct pathogenic mechanisms of GLILD, possibly deriving from diverse triggers correlating with specific clinical and prognostic phenotypes [118,119]. Further evidence is needed to define the exact pathogenic, diagnostic and prognostic role of these lymphocyte sub-populations in GLILD. The role of trans-bronchial biopsy is not defined, being cryo-biopsy, as for other ILDS, a more promising approach than EBUS-TBNA $[108,120]$.

Specific therapeutic guidelines for GLILD are currently lacking. No evidence from controlled trials is available regarding the appropriate timing for treatment initiation or about specific therapeutic protocols. The only published data derive from retrospective studies [109].

The above-mentioned UK consensus statement summarizes the limited available evidence and recommendations based on experts' experience/opinion, together with some open questions [108]. The first point is to decide whether to treat or not GLILD once a diagnosis has been made. The choice should be based on a combination of clinical and functional parameters. There is no evidence about benefits of treating asymptomatic patients with normal lung function (not declining over time). Optimization of the IgG replacement has been suggested, but there is no demonstration that increasing the dose of administered $\lg G$ has a direct impact on GLILD progression [121,122]. There is also no evidence about the use of antimicrobial prophylaxis. However, considering that GLILD occurs in PAD patients and may be associated with bronchiectasis, it is likely that maintaining an adequate $\lg G$ trough level may be helpful; for the same reason, the antimicrobial and anti-inflammatory properties of antibiotic prophylaxis, as previously discussed, may contribute to lower the degree of lung inflammation.

Symptomatic patients presenting an abnormal or at least declining lung function might be first-line treated with oral corticosteroids $[108,123]$. The decision on whether or how to treat may also be influenced by concomitant extra-pulmonary involvement. A general consensus has been reported for the use, as second-line agents, of azathioprine or mycophenolate, and/or rituximab (95). Successful treatment of GLILD with a combination regimen including rituximab and azathioprine has been recently reported in a retrospective case series [109]. Few recently published case report/series suggested that Rituximab monotherapy might also be a reasonable option [115,124,125]. Rationale and outcome of anti-CD20 treatment in CVID have been recently discussed in a comprehensive review [126]. The use of other drugs as hydroxychloroquine, methotrexate, sirolimus, tacrolimus, and anti-TNF agents has been described in case reports $[108,127,128]$. When an underlying genetic defect is known, e.g. LRBA deficiency or activated $\mathrm{PI} 3 \mathrm{~K}-\delta$ syndrome, a more targeted immunomodulator (respectively, abatacept and rapamycin) might be considered $[129,130]$

The reported efficacy of immune suppressants suggests that, despite infectious agents potentially acting as initial triggers, persistent infection may not substantially contribute to GLILD progression. The promising results obtained with drugs commonly used both in T-cell and B-cell mediated diseases suggest that both lymphocyte sub-populations may play an active role in disease progression. It is not clear, however, if different GLILD phenotypes may be distinguished on the basis of the prominent pathogenic role of either of these two lymphocytes subgroups. Rituximab and Azathioprine may improve Treg cells count $[100,131,132]$. Moreover, Rituximab has been successfully used for T-mediated and granulomatous diseases [133]. Recently, a B cell activating factor (BAFF)-driven B cell hyperplasia has been shown to be involved in the pathogenesis of 
ILD in CVID [125]. This further strengthens the rationale of antiCD20 therapy, opening the way also to anti-BAFF therapy. Whether a tailored choice of the most appropriate treatment might be extrapolated by the histologic pattern or by any disease biomarker (e.g peripheral blood or BALF-derived mediators or lymphocyte distribution) is still an open question.

\subsection{Neoplastic diseases involving the lung}

Cancer is a relevant cause of morbidity and mortality in Primary Antibody Deficiencies. Lymphoma and gastric carcinoma are the most represented neoplastic diseases $[6,13,56]$. Primary lymphoid lesions may affect the lung of PAD patients, including nonHodgkin lymphomas, as low-grade B-cell lymphoma of mucosaassociated lymphoid tissue (MALT), and Hodgkin disease $[134,135]$. Of note, the diagnosis of Epstein-Barr Virus (EBV)driven lymphoproliferative diseases in patients with hypogammaglobulinemia and history of recurrent bacterial infections should raise the suspicion of a CD27-CD70 axis deficiency [136]. In this case, diagnosis relies on genetic analysis moving the investigated PID from the 'predominantly antibody deficiencies' to the 'diseases of Immune dysregulation with Hemophagocytic Lymphohistiocytosis and EBV susceptibility' group of the IUIS classification [1]. Neoplastic lymphoproliferative diseases should be considered in the differential diagnosis of GLILD [137]. Different case series reported also lung carcinoma in CVID patients, but lung infiltration with metastases of other cancers appears to be more common than primary lung tumors [56,92,135]. Even if an increased prevalence of malignant lymphoma and of gastric cancer has been observed in an Italian cohort of 455 CVID patients, the prevalence of lung cancer in that cohort was $0.9 \%$, lower than that reported in general population, with a significantly lower mortality if compared to normative Italian population [13]. A Thymic enlargement/mass at chest CT scan in a patients with hypogammaglobulinemia, finally, should raise the suspicion of a Thymoma-associated Good's Syndrome [138].

\section{Conclusions}

Lung disease is a common and relevant clinical feature of Primary Antibody Deficiency. The availability of different options of IgG replacement therapy, allowing treatment personalization, has significantly reduced the recurrence of infections, particularly in early diagnosed patients. However, diagnostic delay still represents a great concern, particularly for PAD presenting in the adulthood, and once the lung damage is established, the risk of colonization and further infections increases [10]. Moreover, IgG replacement does not fulfill all the patients' requirements, and the persistence of $\lg \mathrm{A}$ and $\operatorname{lgM}$ deficiency and other concomitant immune defects have extensively been highlighted as risk factors for the progression of lung disease [31]. Apart from replacement therapy, no specific and evidence-based guidelines for diagnostic and therapeutic management of lung diseases in PADs are currently available [14]. The most relevant new data, in the field, are those recently published about antibiotic prophylaxis with azithromycin [70]. The management of bronchiectasis, asthma, and COPD might be somehow borrowed from the same conditions occurring in non-PAD patients, provided that the PAD condition had been diagnosed and Ig replacement therapy had been established. Nonetheless, further specific evidence is needed in cohorts of PAD patients. On the contrary, the management of ILD is much more challenging. Too little is known about pathogenesis, and about correlations between histology, radiology, serum markers, and disease behavior. Moreover, the need for a tailored treatment which could maximize the effect on lung disease while minimizing the immune suppressive power, particularly when acting broader than on B-cell mediated immunity, is definitely higher in PAD than in immune competent patients [139]. Immunemediated diseases, indeed, do not necessarily occur separately from chronic infection-related lung disease.

Thus, future studies are needed, as well as a broader degree of awareness of epidemiologic and etiologic relationships between PADs and specific pulmonary manifestations. A better understanding of the specific mechanisms leading from immunodeficiency to immune dysregulation, particularly when an underlying monogenic defect cannot be demonstrated, will open the way to more personalized diagnostic and therapeutic approaches. The reduction of diagnostic delay and a better understanding of lung diseases mechanisms and consequent therapeutic options will have a strong impact on Quality of Life and long-term prognosis of PAD patients.

\section{Expert opinion}

\subsection{Practical approach to lung disease in PADs}

Lacking internationally recognized guidelines about screening and management of lung diseases in PAD patients, different approaches are ongoing in distinct Countries and, sometimes, even in different referral centers within the same Country [14]. What we currently recommend in Italy is to adopt a standardized approach at diagnosis and a personalized approach during follow-up, keeping in mind the abovementioned possible pulmonary complications and their preclinical and clinical signs [140]. The initial work-up of a possible lung disease in PAD includes high-resolution chest CT scan and Pulmonary function tests encompassing spirometry (with eventual post-bronchodilator test or methacholine challenge), gas transfer measurement and blood gas analysis [12]. It is indeed important to establish whether patients present or not bronchiectasis, lymph-node enlargement, radiological signs of ILDs, as well as an obstructive, restrictive or combined respiratory disorder, possibly associated with an impairment in gas transfer or blood oxygenation. As discussed above, this initial assessment allows clinicians to optimize Ig replacement therapy and all the possible add-ons, including antibiotic prophylaxis and inhalation therapy. At the time of the initial assessment, a lung MRI may be considered as a complementary investigation. Lung MRI is performed in contexts where recurrent lung imaging may be required, as a radiation-sparing techniques, e.g. in cystic fibrosis; radiologists may thus be used to evaluate signatures of chronic lung disease, including bronchiectasis. The reliability of lung MRI in PAD patients has already been demonstrated in previous studies, and its use in routine monitoring will likely increase in the next future $[141,142]$. This radiation-sparing technique has 
indeed a great potential for application in PAD patients, which are often young and more prone to cancer than the general population.

The initial work-up has to include a genetic screening for the well-known mutations associated to PAD phenotypes and related lung involvement, together with all the investigations possibly highlighting risk factors for specific lung disease patterns (we already discussed the putative risk factors for GLILD, e.g. splenomegaly and percentage expansion of CD21low B cells).

Ig replacement therapy has to be established at the dosage of $400-800 \mathrm{mg} / \mathrm{kg}$ every 4 weeks, adjusting the initial dose according to the frequency of infections and lgG trough levels. The route and the schedule of administration and the optimal replacement dosage have to be individualized [143]. No specific difference between intravenous (IVIg) and subcutaneous (SClg) administration of $\mathrm{lg}$ has been clearly demonstrated, in terms of impact on PAD-related lung complications, despite a lower degree of bronchiectasis under SClg treatment having been described in certain cohorts of patients [76]. The main goal is to obtain and keep stable the optimal lgG trough level for each single patient, independent on route of lg administration. According to recent evidence, apart from Ig replacement therapy, in patients presenting bronchiectasis or COPD, we recommend to establish an antibiotic prophylaxis with azithromycin, if not contraindicated. A supervised Pulmonary Rehabilitation and Exercise Training programs should be recommended to patients suffering from bronchiectasis and/or COPD complaining frequent acute exacerbations.

In case of suspicion of ILD raising from the initial work-up, 6-MWT and/or a CPET test should be promptly performed. According to the results of functional assessment and to the presence or absence of symptoms, patients might be then recommended either a therapeutic approach or a watchful waiting strategy. In this second circumstance, not only a functional but also a radiologic close monitoring is needed. Thus, despite HRCT being the current gold standard imaging technique, the importance of Lung MRI is destined to increase [144,145].

Once a clinical and radiologic suspicion of GLILD has been formulated, a bronchoalveolar lavage is recommended to rule out an infection as cause of the interstitial lung disease. The role of BALF lymphocyte flow-cytometric analysis in the diagnostic process is not yet defined. Nonetheless, preliminary data suggested a possible relationship between the lymphocyte subpopulations distribution and the clinical behavior of GLILD [117-119]. BALF lymphocytes may be helpful in the diagnostic work-up of ILDs, including sarcoidosis. In this last case, in specific circumstances, a definite diagnosis of sarcoidosis may rely on the combination between a suggestive clinical-radiologic picture and a CD4/CD8 ratio [90]. Moreover, an increase in $B$ cells may allow to assess a possible clonal restriction of surface Ig light chains and, in case malignancies had been ruled out, might suggest a more B-cell targeted approach with antiCD20 treatment. Positron emission tomography with FluoroD-glucose (FDG-PET) combined with CT scan (or with MRI, when available) represents a reasonable option in the work-up, combining a well-established role in the differential diagnosis of lymphoproliferative disease and a recently described value in initial work-up and in response-to-treatment evaluation of
GLILD. Finally, to confirm a diagnosis of GLILD versus the suspicion of lymphoma, a histologic examination is required. Transbronchial biopsy generally offers small samples, that may be inadequate to observe the typical histologic heterogeneity of GLILD and to exclude a malignant lymphoproliferative disease. Thus, an open-lung or VATS biopsy is currently recommended as above described. However, in the field of ILDs, transbronchial cryo-biopsy has been gaining importance over the last few years, offering more adequate samples while sparing the higher risks potentially related to surgery $[108,120]$. At present, in light of the just mentioned risks and of the lack of evidence about any specific treatment of GLILD, in absence of symptoms and without signs of functional decline, the opportunity of an invasive approach should be carefully evaluated by clinicians and discussed with patients. In our opinion, in these circumstances and once ruled out infections and lymphomas (a lymph-node transbronchial biopsy might be enough in many cases and a bronchoalveolar lavage might offer much information), a watchful waiting might be more cost-effective than an immediate surgical lung biopsy. Thus, we suggest establishing a close monitoring schedule, with the evaluation of lung function after 3 months and, later, every 6 months. Chest CT scan should be repeated after 6 months and, subsequently, once a year or according to specific requirements. Once more, lung $M R I$ is destined to become a cornerstone of the watchful waiting strategy. However, at the first evidence of disease progression, surgical lung biopsy is still recommended, provided that we still do not know how a specific histologic or histochemical pattern of GLILD may influence our therapeutic strategy.

Regarding GLILD treatment, first of all, we recommend treating symptomatic patients and those presenting a clear decline in lung function. Treatment of asymptomatic patients without decline in lung function might only be considered in those patients with radiologic evidence of disease progression and a specific underlying genetic defect (e.g. LRBA deficiency), where disease biology may at present be better predicted and targeted. The increase in serum lgM levels has also been suggested as a marker of more severe disease behavior that should be taken into account [125]. Optimization of Ig replacement therapy is reasonable, both for preventing acute respiratory exacerbations and for down-modulating any possible infection-related inflammatory trigger. The first-line steroid treatment is a standard approach in inflammatory ILDs and may be considered in the presence of an Organizing Pneumonia predominant pattern. In most of other cases and particularly when granulomatous inflammation is detected, in the absence of therapeutic guidelines, we take some hints from our experience in the treatment of chronic sarcoidosis. Since a long-term treatment is generally needed, the use of steroids alone is generally burdened by many side effects even in immunocompetent patients. Thus, we prefer to use corticosteroids as induction treatment while starting an immunosuppressant as Azathioprine or Mycophenolate to be continued as long-term treatment. However, when a rapid clinical response is needed, our first choice tends to be the anti-CD20 treatment with Rituximab, that has been shown effective in different ILD contexts, including selected cases of sarcoidosis and GLILD [125,133]. 
In terms of routine follow-up, finally, lung function (particularly FEV1 and DLCO) is known to decline slowly over time in patients with PID, despite appropriate replacement therapy [67]. Thus, annual testing with spirometry and CO transfer measurement is recommended in PAD patients, with or without functional or radiologic evidence of chronic lung disease. As already discussed, DLCO reduction may be an early signal of an ongoing, clinically not evident, interstitial lung disease, even in the absence of a restrictive pattern at PFTs. HRCT scan can be even more sensitive, showing interstitial modifications before any impairment in gas transfer. However, due to the exposure to ionizing radiations, CT scan is generally recommended to be performed once every 5 years in the absence of specific clinical indications. The increasing performances of chest MRI will hopefully allow clinicians to prescribe more frequent imaging assessments, particularly in selected patients with known risk factors for ILD. This will also be helpful in those patients with a diagnosis of GLILD without immediate indication to treatment. Figure 3 recapitulates the step-bystep approach to lung monitoring in PADs.

Starting from recent evidence and open questions already discussed in this review, in the next 3-5 years we expect to have some major advances that will significantly modify (and standardize) the management of lung disease in PAD:

(1) In PAD patients, IgG replacement therapy has been shown to enhance survival and reduce severe and invasive infections. However, patients might still develop chronic infection-related lung disease (CLD). Recurrent respiratory tract infections are indeed linked to low serum IgA levels, reflecting a severely impaired isotype switching process leading to a loss of function of memory $B$ cells. It has been recently suggested that there have been limited innovations over the last 65 years in $\mathrm{lg}$
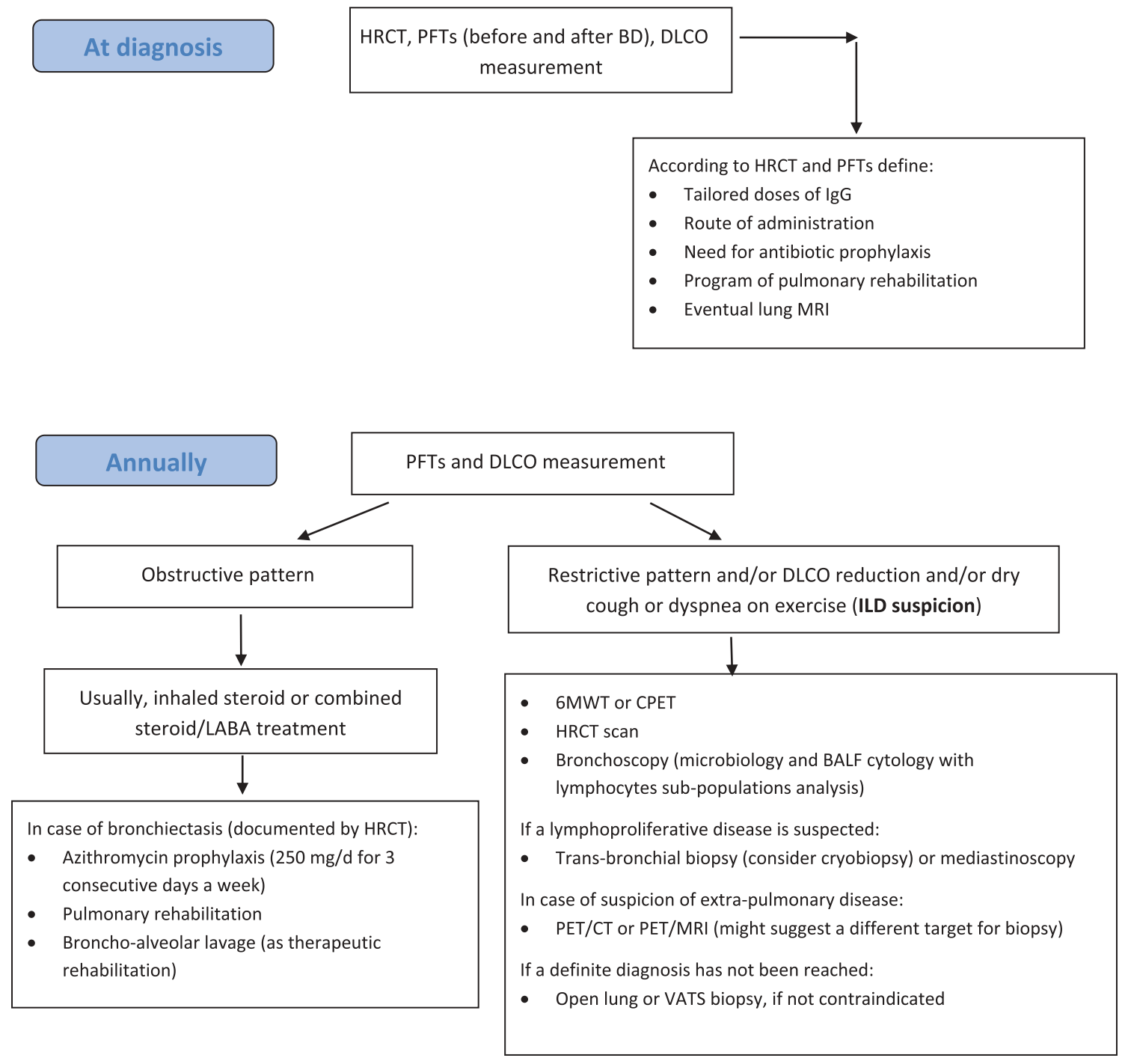

$$
\text { Every } 5 \text { years }
$$

HRCT scan (consider MRI)

Figure 3. Monitoring and management of lung disease in primary antibody deficiencies. 
replacement therapy. Despite having improved the therapeutic options in terms of route and schedule of administration and tolerability of the different preparations, indeed, we are still not able to provide IgA or IgM replacement [146]. IgA and IgM enriched preparations are currently under evaluation, being the lack of the secretory domain the main limitations, at present. Recently, recombinant secretory component to be combined with plasma-derived IgA and IgM have been tested in animal studies with promising results. Human plasma-derived polyreactive IgA and IgM antibodies reconstituted as secretory-like immunoglobulins have been shown to be effective when used for oral passive immunization in murine models of experimental salmonellosis [147]. Nebulized inhaled $\lg (\lg A / \lg M)$, will also be available in the near future [148]. These new preparations might be useful to prevent the progression of CLD and will offer a therapeutic option for SIgAD and selective IgM deficiency patients. The potential limitation might be represented by the development of anti-lgA IgG (and possibly $\operatorname{lgM}$ ) antibodies, potentially inducing anaphylactoid reactions to IgA-containing preparations $[149,150]$. However, the risk will be limited to those patients with absolute IgA deficiency (undetectable $\lg A$ ) and still able to produce specific lgG (or IgM); the subcutaneous route of administration has been shown to be safer, in these patients [149].

(2) As suggested above, recent evidence supports the possible role of lung magnetic resonance imaging (MRI) in diagnosing and monitoring chronic lung disease in PAD patients. On the other hand, in ILDs the potential of MRI is much more uncertain. Accordingly, future multicentric studies will be needed due to the lower number of PAD patients presenting GLILD if compared to bronchiectasis. However, thin-slices chest CT scan cannot distinguish pure inflammatory from fibrotic groundglass opacity. On the contrary, recently developed chest MRI techniques, while not adding information to HRCT scan in terms of image quality, may provide in ILDs both structural and functional information in a single examination. They can indeed add information about inflammation, ventilation, and perfusion, being potentially helpful in assessing ILD progression and in predicting its response to treatment $[144,145]$. All these considered, without exposure to ionizing radiation, chest MRI will offer also in PAD-associated ILDs better tissue characterization, differentiating between inflammatory and purely fibrotic ground-glass opacities [144]. Recent and near-future advances will thus hopefully lead to the routine use of lung MRI at diagnosis, in a combined approach together with HRCT, and as gold standard for the 3-5 years follow-up in PAD patients, being HRCT used only on demand.

(3) The recent controlled trial on Azithromycin prophylaxis will be helpful in designing a more standardized approach to CLD in PAD patients. However, further multicenter-controlled trials are needed, in order to define PAD-specific evidence-based guidelines for the management of infection-related lung diseases.
(4) The diagnosis of GLILD is currently based on a multi-step process culminating in an invasive open-lung or VATS biopsy. The increasing awareness of this lung complication will hopefully lead to earlier suspicion and to more limited risks eventually related to a surgical biopsy. However, the world of ILDs is moving towards clinicalradiologic diagnoses based on the exclusion of causes of secondary lung diseases and on a Multi-Disciplinary Team (MDT) discussion. Thus, the diagnosis of GLILD is also destined to move to a more clinical-radiologicalplus -MDT -discussion-based approach. VATS and openlung biopsy will then be limited to those cases when other lung diseases cannot be ruled out in a different way (e.g. transbronchial biopsy or biopsy of a different tissue in the context of a systemic disease). Cryo-biopsy will likely become the first-line approach when a lung tissue biopsy is needed.

(5) The treatment of GLILD definitely represents the major concern. Observational studies are ongoing but, due to the rarity and heterogeneity of this condition, we are still far from multicenter interventional-controlled studies possibly leading to evidence-based guidelines. Thus, the next advances will still derive from case series and retrospective/prospective observational studies. Nonetheless, these studied will start providing interesting correlations between possible predisposing factors, concomitant conditions, peripheral blood or BALF lymphocytes distribution (e.g. CD4/CD8 ratio, CD21lo $B$ cells or large granular lymphocytes expansion), histochemical characterization of tissue samples and GLILD behavior. The recent paper published by Maglione et al. represents an appropriate paradigm of this kind of studies [125]. Response to treatment will also be put in relation to all the above and to possible underlying genetic defects sustaining a peculiar pathogenic pathway. This will allow clinicians either to classify patients in different subgroups in terms of prognosis and predicted response to specific treatment, or to take into account all the possible immunologic mechanisms or biomarkers of each single patients in order to design a tailored treatment strategy.

(6) Starting from these data that will hopefully be published in the next 3-5 years, it will be possible to design relatively large multicenter-controlled trial with existing drugs that will be the basis for PAD-specific evidencebased treatment guidelines for ILDs.

\section{Acknowledgments}

Thanks to Nicholas Landini, MD, Department of Radiology, Ca' Foncello Hospital, Treviso, Italy, for his contribution to the selection of the radiologic images.

\section{Funding}

This paper was not funded. 


\section{Declaration of interest}

The authors have no relevant affiliations or financial involvement with any organization or entity with a financial interest in or financial conflict with the subject matter or materials discussed in the manuscript. This includes employment, consultancies, honoraria, stock ownership or options, expert testimony, grants or patents received or pending, or royalties.

\section{Reviewer disclosures}

Peer reviewers on this manuscript have no relevant financial or other relationships to disclose.

\section{References}

Papers of special note have been highlighted as either of interest $(\cdot)$ or of considerable interest $(\cdot \bullet)$ to readers.

1. Bousfiha A, Jeddane L, Picard C, et al. The 2017 IUIS phenotypic classification for primary immunodeficiencies. J Immunol Clin. 2018 Jan;38(1):129-143. PubMed PMID: 29226301; PubMed Central PMCID: PMCPMC5742599.

2. Picard C, Bobby Gaspar H, Al-Herz W, et al. International Union of Immunological Societies: 2017 primary immunodeficiency diseases committee report on inborn errors of immunity. J Clin Immunol. 2018 Jan;38(1):96-128. PubMed PMID: 29226302; PubMed Central PMCID: PMCPMC5742601.

3. Kobrynski L, Powell RW, Bowen S. Prevalence and morbidity of primary immunodeficiency diseases, United States 2001-2007. J Clin Immunol. 2014 Nov;34(8):954-961. PubMed PMID: 25257253; PubMed Central PMCID: PMCPMC4820073.

4. Bousfiha AA, Jeddane L, Ailal F, et al. Primary immunodeficiency diseases worldwide: more common than generally thought. J Clin Immunol. 2013 Jan;33(1):1-7. PubMed PMID: 22847546.

5. Mortaz E, Tabarsi P, Mansouri D, et al. Cancers Related to Immunodeficiencies: update and Perspectives. Front Immunol. 2016;7:365. PubMed PMID: 27703456; PubMed Central PMCID: PMCPMC5028721

6. Quinti I, Agostini C, Tabolli S, et al. Malignancies are the major cause of death in patients with adult onset common variable immunodeficiency. Blood. 2012 Aug 30;120(9):1953-1954. PubMed PMID: 22936739.

7. Mahlaoui NG, Kindle B, Ehl G. on behalf of the ESID registry working party steering committee and the ESID society. The European Society for Immunodeficiencies (ESID) Registry: recent advancements in the epidemiology of Primary Immunodeficiencies and how does that translate in clinical care. Rare Dis Orphan Drugs J. 2014 Dec;1(4 Suppl. 4):25-27.

8. Durandy A, Kracker S, Fischer A. Primary antibody deficiencies. Nat Rev Immunol. 2013 Jul;13(7):519-533. PubMed PMID: 23765059

9. Bonilla FA, Barlan I, Chapel H, et al. International Consensus Document (ICON): common Variable Immunodeficiency Disorders. J Allergy Clin Immunol Pract. 2016 Jan-Feb;4(1):38-59. PubMed PMID: 26563668; PubMed Central PMCID: PMCPMC4869529.

10. Odnoletkova I, Kindle G, Quinti I, et al. The burden of common variable immunodeficiency disorders: a retrospective analysis of the European Society for Immunodeficiency (ESID) registry data. Orphanet J Rare Dis. 2018 Nov 12;13(1):201. PubMed PMID: 30419968; PubMed Central PMCID: PMCPMC6233554.

- Retrospective analysis of CVID patients included in the ESID registry: updated report on the burden of disease.

11. Hampson FA, Chandra A, Screaton NJ, et al. Respiratory disease in common variable immunodeficiency and other primary immunodeficiency disorders. Clin Radiol. 2012 Jun;67(6):587-595. PubMed PMID: 22226567.

12. Cinetto F, Scarpa R, Rattazzi $M$, et al. The broad spectrum of lung diseases in primary antibody deficiencies. Eur Respir Rev. 2018 Sep 30;27(149):180019. PubMed PMID: 30158276.
13. Pulvirenti F, Pecoraro A, Cinetto F, et al. Gastric cancer is the leading cause of death in Italian adult patients with common variable immunodeficiency. Front Immunol. 2018;9:2546. PubMed PMID: 30455695; PubMed Central PMCID: PMCPMC6230622.

14. Jolles S, Sanchez-Ramon S, Quinti I, et al. Screening protocols to monitor respiratory status in primary immunodeficiency disease: findings from a European survey and subclinical infection working group. Clin Exp Immunol. 2017 Nov; 190(2):226-234. PubMed PMID: 28708268; PubMed Central PMCID: PMCPMC5629444.

15. Freeman AF, Holland SM. Antimicrobial prophylaxis for primary immunodeficiencies. Curr Opin Allergy Clin Immunol. 2009 Dec;9 (6):525-530. PubMed PMID: 19812481.

16. Schussler E, Beasley MB, Maglione PJ. Lung disease in primary antibody deficiencies. J Allergy Clin Immunol Pract. 2016 Nov Dec;4(6):1039-1052. PubMed PMID: 27836055; PubMed Central PMCID: PMCPMC5129846.

17. Quinti I, Soresina A, Spadaro G, et al. Long-term follow-up and outcome of a large cohort of patients with common variable immunodeficiency. J Clin Immunol. 2007 May;27(3):308-316. PubMed PMID: 17510807.

18. Verma N, Grimbacher B, Hurst JR. Lung disease in primary antibody deficiency. Lancet Respir Med. 2015 Aug;3(8):651-660. PubMed PMID: 26188881.

19. Quinti I, Soresina A, Guerra A, et al. Effectiveness of immunoglobulin replacement therapy on clinical outcome in patients with primary antibody deficiencies: results from a multicenter prospective cohort study. J Clin Immunol. 2011 Jun;31(3):315-322. PubMed PMID: 21365217.

20. Maglione PJ. Autoimmune and Lymphoproliferative Complications of Common Variable Immunodeficiency. Curr Allergy Asthma Rep. 2016 Mar;16(3):19. PubMed PMID: 26857017.

21. Ludvigsson JF, Neovius M, Hammarstrom L. Association between IgA deficiency \& other autoimmune conditions: a population-based matched cohort study. J Clin Immunol. 2014 May;34(4):444-451. PubMed PMID: 24584841.

22. Chapel H, Lucas M, Patel S, et al. Confirmation and improvement of criteria for clinical phenotyping in common variable immunodeficiency disorders in replicate cohorts. J Allergy Clin Immunol. 2012 Nov;130(5):1197-1198 e9. PubMed PMID: 22819511.

23. Hurst JR, Workman S, Garcha DS, et al. Activity, severity and impact of respiratory disease in primary antibody deficiency syndromes. J Clin Immunol. 2014 Jan;34(1):68-75. PubMed PMID: 24136152.

24. Lucas $M$, Lee $M$, Lortan J, et al. Infection outcomes in patients with common variable immunodeficiency disorders: relationship to immunoglobulin therapy over 22 years. J Allergy Clin Immunol. 2010 Jun;125(6):1354-1360 e4. PubMed PMID: 20471071.

25. Sperlich JM, Grimbacher B, Workman S, et al. Respiratory infections and antibiotic usage in common variable immunodeficiency. J Allergy Clin Immunol Pract. 2017 Jul 19. DOI:10.1016/j. jaip.2017.05.024. PubMed PMID: 28734862.

26. Lougaris V, Sorlini A, Monfredini C, et al. Clinical and laboratory features of 184 Italian pediatric patients affected with selective IgA Deficiency (SlgAD): a longitudinal single-center study. J Clin Immunol. 2019 May 25. DOI:10.1007/s10875-019-00647-y. PubMed PMID: 31129864.

27. Parker AR, Skold M, Ramsden DB, et al. The clinical utility of measuring $\lg G$ subclass immunoglobulins during immunological investigation for suspected primary antibody deficiencies. Lab Med. 2017 Nov 8;48(4):314-325. PubMed PMID: 29126302; PubMed Central PMCID: PMCPMC5907904.

28. Filion CA, Taylor-Black S, Maglione PJ, et al. Differentiation of common variable immunodeficiency from lgG deficiency. J Allergy Clin Immunol Pract. 2019 Apr;7(4):1277-1284. PubMed PMID: 30557717; PubMed Central PMCID: PMCPMC6519441.

29. de la Morena MT. Clinical Phenotypes of Hyper-IgM Syndromes. J Allergy Clin Immunol Pract. 2016 Nov - Dec;4(6):1023-1036. PubMed PMID: 27836054.

30. Davies EG, Thrasher AJ. Update on the hyper immunoglobulin $M$ syndromes. Br J Haematol. 2010 Apr;149(2):167-180. PubMed PMID: 20180797; PubMed Central PMCID: PMCPMC2855828. 
31. Mooney D, Edgar D, Einarsson G, et al. Chronic lung disease in common variable immune deficiency (CVID): a pathophysiological role for microbial and non-B cell immune factors. Crit Rev Microbiol. 2017 Aug;43(4):508-519. PubMed PMID: 28068853.

32. Duraisingham SS, Manson A, Grigoriadou S, et al. Immune deficiency: changing spectrum of pathogens. Clin Exp Immunol. 2015 Aug;181(2):267-274. PubMed PMID: 25677249; PubMed Central PMCID: PMCPMC4516442.

33. Chen $Y$, Stirling RG, Paul $E$, et al. Longitudinal decline in lung function in patients with primary immunoglobulin deficiencies. J Allergy Clin Immunol. 2011 Jun;127(6):1414-1417. PubMed PMID: 21546068.

34. Stubbs A, Bangs C, Shillitoe B, et al. Bronchiectasis and deteriorating lung function in agammaglobulinaemia despite immunoglobulin replacement therapy. Clin Exp Immunol. 2018 Feb;191 (2):212-219. PubMed PMID: 28990652; PubMed Central PMCID: PMCPMC5758375.

35. Azoulay E, Bergeron A, Chevret $\mathrm{S}$, et al. Polymerase chain reaction for diagnosing pneumocystis pneumonia in non-HIV immunocompromised patients with pulmonary infiltrates. Chest. 2009 Mar;135 (3):655-661. PubMed PMID: 19265086.

36. Eyzaguirre $E$, Haque AK. Application of immunohistochemistry to infections. Arch Pathol Lab Med. 2008 Mar;132(3):424-431. PubMed PMID: 18318584.

37. Kainulainen L, Nikoskelainen J, Vuorinen $T$, et al. Viruses and bacteria in bronchial samples from patients with primary hypogammaglobulinemia. Am J Respir Crit Care Med. 1999 Apr;159(4 Pt 1):1199-1204. PubMed PMID: 10194166.

38. Oksenhendler E, Gerard L, Fieschi C, et al. Infections in 252 patients with common variable immunodeficiency. Clin Infect Dis. 2008 May 15;46(10):1547-1554. PubMed PMID: 18419489.

39. Arkwright PD, Gennery AR. Ten warning signs of primary immunodeficiency: a new paradigm is needed for the 21st century. Ann N Y Acad Sci. 2011 Nov;1238:7-14. PubMed PMID: 22129048.

40. Jesenak M, Banovcin P, Jesenakova B, et al. Pulmonary manifestations of primary immunodeficiency disorders in children. Front Pediatr. 2014;2:77. PubMed PMID: 25121077; PubMed Central PMCID: PMCPMC4110629.

41. Kainulainen L, Vuorinen T, Rantakokko-Jalava K, et al. Recurrent and persistent respiratory tract viral infections in patients with primary hypogammaglobulinemia. J Allergy Clin Immunol. 2010 Jul;126 (1):120-126. PubMed PMID: 20541246.

42. Kralickova $P$, Mala E, Vokurkova $D$, et al. Cytomegalovirus disease in patients with common variable immunodeficiency: three case reports. Int Arch Allergy Immunol. 2014;163(1):69-74. PubMed PMID: 24247002

43. Fried AJ, Bonilla FA. Pathogenesis, diagnosis, and management of primary antibody deficiencies and infections. Clin Microbiol Rev. 2009 Jul;22(3):396-414. PubMed PMID: 19597006; PubMed Central PMCID: PMCPMC2708392.

44. Jongco AM, Gough JD, Sarnataro K, et al. X-linked agammaglobulinemia presenting as polymicrobial pneumonia, including Pneumocystis jirovecii. Ann Allergy Asthma Immunol. 2014 Jan;112(1):74-75 e2. PubMed PMID: 24331399; PubMed Central PMCID: PMCPMC3875599.

45. Eijkhout HW, van Der Meer JW, Kallenberg CG, et al. The effect of two different dosages of intravenous immunoglobulin on the incidence of recurrent infections in patients with primary hypogammaglobulinemia. A randomized, double-blind, multicenter crossover trial. Ann Intern Med. 2001 Aug 7;135(3):165-174. PubMed PMID: 11487483.

46. Roifman CM, Levison H, Gelfand EW. High-dose versus low-dose intravenous immunoglobulin in hypogammaglobulinaemia and chronic lung disease. Lancet. 1987 May 9;1(8541):1075-1077. PubMed PMID: 2883406.

47. Plebani A, Soresina A, Rondelli R, et al. Clinical, immunological, and molecular analysis in a large cohort of patients with X-linked agammaglobulinemia: an Italian multicenter study. Clin Immunol. 2002 Sep;104(3):221-230. PubMed PMID: 12217331.
48. Thickett KM, Kumararatne DS, Banerjee AK, et al. Common variable immune deficiency: respiratory manifestations, pulmonary function and high-resolution CT scan findings. QJM. 2002 Oct;95 (10):655-662. PubMed PMID: 12324637.

49. Schutz K, Alecsandru D, Grimbacher B, et al. Imaging of bronchial pathology in antibody deficiency: data from the European Chest CT Group. J Clin Immunol. 2019 Jan;39(1):45-54. PubMed PMID: 30547383

50. Moschese V, Chini L, Graziani S, et al. Follow-up and outcome of symptomatic partial or absolute IgA deficiency in children. Eur J Pediatr. 2019 Jan;178(1):51-60. PubMed PMID: 30269248.

51. Pulvirenti F, Camilli R, Giufre M, et al. Risk factors for Haemophilus influenzae and pneumococcal respiratory tract colonization in CVID. J Allergy Clin Immunol. 2018 Dec;142(6):1999-2002 e3. PubMed PMID: 30170126.

52. Edgar JD, Buckland M, Guzman D, et al. The United Kingdom Primary Immune Deficiency (UKPID) Registry: report of the first 4 years' activity 2008-2012. Clin Exp Immunol. 2014 Jan;175(1):68-78. PubMed PMID: 23841717; PubMed Central PMCID: PMCPMC3898556.

53. Cole PJ. Inflammation: a two-edged sword-the model of bronchiectasis. Eur J Respir Dis Suppl. 1986;147:6-15. PubMed PMID: 3533593.

54. Hurst JR, Elborn JS, De Soyza A, et al. COPD-bronchiectasis overlap syndrome. Eur Respir J. 2015 Feb;45(2):310-313. PubMed PMID: 25653262.

55. Livnat G, Bentur L. Non-cystic fibrosis bronchiectasis: review and recent advances. F1000 Med Rep. 2009 Aug; 26. 1. DOI:10.3410/M167. PubMed PMID: 20948713; PubMed Central PMCID: PMCPMC2948306.

56. Brent J, Guzman D, Bangs C, et al. Clinical and laboratory correlates of lung disease and cancer in adults with idiopathic hypogammaglobulinaemia. Clin Exp Immunol. 2016 Apr;184 (1):73-82. PubMed PMID: 26646609; PubMed Central PMCID: PMC4778100.

57. Spagnolo P, Fabbri LM, Bush A. Long-term macrolide treatment for chronic respiratory disease. Eur Respir J. 2013 Jul;42(1):239-251. PubMed PMID: 23180583.

58. Khan TZ, Wagener JS, Bost T, et al. Early pulmonary inflammation in infants with cystic fibrosis. Am J Respir Crit Care Med. 1995 Apr;151 (4):1075-1082. PubMed PMID: 7697234.

59. EIMaraachli W, Conrad DJ, Wang AC. Using cystic fibrosis therapies for non-cystic fibrosis bronchiectasis. Clin Chest Med. 2016 Mar;37 (1):139-146. PubMed PMID: 26857775.

60. Saiman L, Anstead M, Mayer-Hamblett N, et al. Effect of azithromycin on pulmonary function in patients with cystic fibrosis uninfected with Pseudomonas aeruginosa: a randomized controlled trial. JAMA. 2010 May 5;303(17):1707-1715. PubMed PMID: 20442386.

61. Equi A, Balfour-Lynn IM, Bush A, et al. Long term azithromycin in children with cystic fibrosis: a randomised, placebo-controlled crossover trial. Lancet. 2002 Sep 28;360(9338):978-984. PubMed PMID: 12383667.

62. Wong C, Jayaram L, Karalus $\mathrm{N}$, et al. Azithromycin for prevention of exacerbations in non-cystic fibrosis bronchiectasis (EMBRACE): a randomised, double-blind, placebo-controlled trial. Lancet. 2012 Aug 18;380(9842):660-667. PubMed PMID: 22901887.

63. Albert RK, Connett J, Bailey WC, et al. Azithromycin for prevention of exacerbations of COPD. N Engl J Med. 2011 Aug 25;365 (8):689-698. PubMed PMID: 21864166; PubMed Central PMCID: PMCPMC3220999.

64. Altenburg J, de Graaff CS, Stienstra Y, et al. Effect of azithromycin maintenance treatment on infectious exacerbations among patients with non-cystic fibrosis bronchiectasis: the BAT randomized controlled trial. JAMA. 2013 Mar 27;309(12):1251-1259. PubMed PMID: 23532241

65. Ballow M, Paris K, de la Morena M. Should antibiotic prophylaxis be routinely used in patients with antibody-mediated primary immunodeficiency? J Allergy Clin Immunol Pract. 2017 Dec 21 DOI:10.1016/j.jaip.2017.11.024. PubMed PMID: 29274825.

66. Bonilla FA, Khan DA, Ballas ZK, et al. Practice parameter for the diagnosis and management of primary immunodeficiency. 
J Allergy Clin Immunol. 2015 Nov;136(5):1186-205 e1-78. PubMed PMID: 26371839.

67. Rich $A L$, Le Jeune IR, McDermott $L$, et al. Serial lung function tests in primary immune deficiency. Clin Exp Immunol. 2008 Jan;151 (1):110-113. PubMed PMID: 18005259; PubMed Central PMCID: PMCPMC2276933.

68. Kuruvilla M, de la Morena MT. Antibiotic prophylaxis in primary immune deficiency disorders. J Allergy Clin Immunol Pract. 2013 Nov-Dec;1(6):573-582. PubMed PMID: 24565703.

69. Moschese V, Martire B, Soresina A, et al. Anti-infective prophylaxis for primary immunodeficiencies: what is done in Italian Primary Immunodeficiency Network centers (IPINet) and review of the literature. J Biol Regul Homeost Agents. 2013 Oct-Dec;27 (4):935-946. PubMed PMID: 24382174.

70. Milito C, Pulvirenti F, Cinetto F, et al. Double-Blind, Placebo-Controlled Randomized Trial on Low Dose Azithromycin Prophilaxis in Primary Antibody Deficiencies. J Allergy Clin Immunol. 2019 Mar 22. DOI:10.1016/j.jaci.2019.01.051. PubMed PMID: 30910492.

- First double blind placebo-controlled trial on the use of antibiotic prophylaxis in primary antibody deficiencies.

71. Starner TD, Shrout JD, Parsek MR, et al. Subinhibitory concentrations of azithromycin decrease nontypeable Haemophilus influenzae biofilm formation and Diminish established biofilms. Antimicrob Agents Chemother. 2008 Jan;52(1):137-145. PubMed PMID: 17954687; PubMed Central PMCID: PMCPMC2223912.

72. Cameron EJ, McSharry C, Chaudhuri R, et al. Long-term macrolide treatment of chronic inflammatory airway diseases: risks, benefits and future developments. Clin Exp Allergy. 2012 Sep;42 (9):1302-1312. PubMed PMID: 22925316.

73. Malhotra-Kumar S, Lammens $C$, Coenen S, et al. Effect of azithromycin and clarithromycin therapy on pharyngeal carriage of macrolide-resistant streptococci in healthy volunteers: a randomised, double-blind, placebo-controlled study. Lancet. 2007 Feb 10;369(9560):482-490. PubMed PMID: 17292768.

74. Renna M, Schaffner C, Brown K, et al. Azithromycin blocks autophagy and may predispose cystic fibrosis patients to mycobacterial infection. J Clin Invest. 2011 Sep;121(9):3554-3563. PubMed PMID: 21804191; PubMed Central PMCID: PMCPMC3163956.

75. Garrod R, Lasserson T. Role of physiotherapy in the management of chronic lung diseases: an overview of systematic reviews. Respir Med. 2007 Dec;101(12):2429-2436. PubMed PMID: 17870457.

76. Shillitoe B, Gennery A. X-Linked Agammaglobulinaemia: outcomes in the modern era. Clin Immunol. 2017 Oct;183:54-62. PubMed PMID: 28729230.

77. Lee $\mathrm{AL}$, Hill $\mathrm{CJ}, \mathrm{McD}$ onald $\mathrm{CF}$, et al. Pulmonary rehabilitation in individuals with non-cystic fibrosis bronchiectasis: a systematic review. Arch Phys Med Rehabil. 2017 Apr;98(4):774-782 e1. PubMed PMID: 27320420.

78. Berger M, Geng B, Cameron DW, et al. Primary immune deficiency diseases as unrecognized causes of chronic respiratory disease. Respir Med. 2017 Nov;132:181-188. PubMed PMID: 29229095.

79. Ozcan C, Metin A, Erkocoglu M, et al. Bronchial hyperreactivity in children with antibody deficiencies. Allergol Immunopathol (Madr). 2015 Jan-Feb;43(1):57-61. PubMed PMID: 24485938.

80. Kim JH, Park S, Hwang YI, et al. Immunoglobulin G subclass deficiencies in adult patients with chronic airway diseases. J Korean Med Sci. 2016 Oct;31(10):1560-1565. PubMed PMID: 27550483; PubMed Central PMCID: PMCPMC4999397.

81. McCullagh BN, Comellas AP, Ballas ZK, et al. Antibody deficiency in patients with frequent exacerbations of Chronic Obstructive Pulmonary Disease (COPD). PLoS One. 2017;12(2):e0172437. PubMed PMID: 28212436; PubMed Central PMCID: PMCPMC5315316

82. Urm SH, Yun HD, Fenta YA, et al. Asthma and risk of selective IgA deficiency or common variable immunodeficiency: a population-based case-control study. Mayo Clin Proc. 2013 Aug;88(8):813-821. PubMed PMID: 23910409; PubMed Central PMCID: PMCPMC3753684.

83. Wirsum C, Glaser C, Gutenberger S, et al. Secondary antibody deficiency in glucocorticoid therapy clearly differs from primary antibody deficiency. J Clin Immunol. 2016 May;36(4):406-412. PubMed PMID: 26980224.

84. Kim JH, Ye YM, Ban GY, et al. Effects of immunoglobulin replacement on asthma exacerbation in adult asthmatics with IgG subclass deficiency. Allergy Asthma Immunol Res. 2017 Nov;9 (6):526-533. PubMed PMID: 28913992; PubMed Central PMCID: PMCPMC5603481.

85. Schwartz HJ, Hostoffer RW, McFadden ER Jr., et al. The response to intravenous immunoglobulin replacement therapy in patients with asthma with specific antibody deficiency. Allergy Asthma Proc. 2006 Jan-Feb;27(1):53-58. PubMed PMID: 16598993.

86. Cowan J, Gaudet L, Mulpuru S, et al. A retrospective longitudinal within-subject risk interval analysis of immunoglobulin treatment for recurrent acute exacerbation of chronic obstructive pulmonary disease. PLoS One. 2015;10(11):e0142205. PubMed PMID: 26558756; PubMed Central PMCID: PMCPMC4641695.

87. Tarzi MD, Grigoriadou S, Carr SB, et al. Clinical immunology review series: an approach to the management of pulmonary disease in primary antibody deficiency. Clin Exp Immunol. 2009 Feb;155(2):147-155. PubMed PMID: 19128358; PubMed Central PMCID: PMCPMC2675244.

88. Wheat $\mathrm{WH}, \mathrm{Cool} C D$, Morimoto $Y$, et al. Possible role of human herpesvirus 8 in the lymphoproliferative disorders in common variable immunodeficiency. J Exp Med. 2005 Aug 15;202 (4):479-484. PubMed PMID: 16103407; PubMed Central PMCID: PMCPMC2212861.

89. Ardeniz O, Cunningham-Rundles $C$. Granulomatous disease in common variable immunodeficiency. Clin Immunol. 2009 Nov;133 (2):198-207. PubMed PMID: 19716342; PubMed Central PMCID: PMCPMC2760682.

90. Cinetto F, Agostini C. Advances in understanding the immunopathology of sarcoidosis and implications on therapy. Expert Rev Clin Immunol. 2016 Sep;12(9):973-988. PubMed PMID: 27101234.

91. Tafuro F, Corradi M. An approach to interpreting restrictive spirometric pattern results in occupational settings. Med Lav. 2016 Dec 13;107(6):419-436. PubMed PMID: 27976661.

92. Yazdani $R$, Abolhassani $H$, Asgardoon $M$, et al. Infectious and noninfectious pulmonary complications in patients with primary immunodeficiency disorders. J Investig Allergol Clin Immunol. 2017;27 (4):213-224. PubMed PMID: 28731410.

93. Popa V, Colby TV, Reich SB. Pulmonary interstitial disease in Ig deficiency. Chest. 2002 Nov;122(5):1594-1603. PubMed PMID: 12426258.

94. Prasse A, Kayser G, Warnatz K. Common variable immunodeficiency-associated granulomatous and interstitial lung disease. Curr Opin Pulm Med. 2013 Sep;19(5):503-509. PubMed PMID: 23880700.

95. Maglione PJ, Ko HM, Beasley MB, et al. Tertiary lymphoid neogenesis is a component of pulmonary lymphoid hyperplasia in patients with common variable immunodeficiency. J Allergy Clin Immunol. 2014 Feb;133(2):535-542. PubMed PMID: 24131823; PubMed Central PMCID: PMCPMC4109033.

96. Kuehn HS, Ouyang W, Lo B, et al. Immune dysregulation in human subjects with heterozygous germline mutations in CTLA4. Science. 2014 Sep 26;345(6204):1623-1627. PubMed PMID: 25213377 PubMed Central PMCID: PMCPMC4371526.

97. Flanagan $S E$, Haapaniemi $E$, Russell $M A$, et al. Activating germline mutations in STAT3 cause early-onset multi-organ autoimmune disease. Nat Genet. 2014 Aug;46(8):812-814. PubMed PMID: 25038750; PubMed Central PMCID: PMCPMC4129488.

98. Lopez-Herrera G, Tampella G, Pan-Hammarstrom Q, et al. Deleterious mutations in LRBA are associated with a syndrome of immune deficiency and autoimmunity. Am J Hum Genet. 2012 Jun 8\%"90(6):986-1001. PubMed PMID: 22608502; PubMed Central PMCID: PMCPMC3370280

99. Buchbinder D, Baker R, Lee YN, et al. Identification of patients with RAG mutations previously diagnosed with common variable immunodeficiency disorders. J Clin Immunol. 2015 Feb;35(2):119-124 PubMed PMID: 25516070; PubMed Central PMCID: PMCPMC4479182.

100. Rao N, Mackinnon AC, Routes JM. Granulomatous and lymphocytic interstitial lung disease: a spectrum of pulmonary histopathologic 
lesions in common variable immunodeficiency - histologic and immunohistochemical analyses of 16 cases. Hum Pathol. 2015 Sep;46(9):1306-1314. PubMed PMID: 26138782; PubMed Central PMCID: PMCPMC4554947.

.. First and comprehensive paper describing histologic features of GLILD.

101. Shokri S, Nabavi M, Hirschmugl T, et al. LPS-responsive beige-like anchor gene mutation associated with possible bronchiolitis obliterans organizing pneumonia associated with hypogammaglobulinemia and normal IgM phenotype and low number of B Cells. Acta Med Iran. 2016 Oct;54(10):620-623. PubMed PMID: 27888588.

102. Sood AK, Funkhouser W, Handly B, et al. Granulomatouslymphocytic interstitial lung disease in 22q11.2 deletion syndrome: a case report and literature review. Curr Allergy Asthma Rep. 2018 Feb 22;18(3):14. PubMed PMID: 29470661; PubMed Central PMCID: PMCPMC5935501.

103. Kaufman J, Komorowski R. Bronchiolitis obliterans organizing pneumonia in common variable immunodeficiency syndrome. Chest. 1991 Aug;100(2):552-553. PubMed PMID: 1864136.

104. Boujaoude Z, Arya R, Rafferty W, et al. Organising pneumonia in common variable immunodeficiency. BMJ Case Rep. 2013 Jun ;7:2013. PubMed PMID: 23749855; PubMed Central PMCID: PMCPMC3702795.

105. Bates CA, Ellison MC, Lynch DA, et al. Granulomatous-lymphocytic lung disease shortens survival in common variable immunodeficiency. J Allergy Clin Immunol. 2004 Aug;114(2):415-421. PubMed PMID: 15316526.

106. Park JH, Levinson Al. Granulomatous-lymphocytic interstitial lung disease (GLILD) in common variable immunodeficiency (CVID). Clin Immunol. 2010 Feb;134(2):97-103. PubMed PMID: 19900842.

107. Verbsky JW, Routes JM. Sarcoidosis and common variable immunodeficiency: similarities and differences. Semin Respir Crit Care Med. 2014 Jun;35(3):330-335. PubMed PMID: 25007085.

108. Hurst JR, Verma N, Lowe $D$, et al. British lung foundation/United Kingdom primary immunodeficiency network consensus statement on the definition, diagnosis, and management of granulomatous-lymphocytic interstitial lung disease in common variable immunodeficiency disorders. J Allergy Clin Immunol Pract. 2017 Jul - Aug;5(4):938-945. PubMed PMID: 28351785.

- It is the only available expert consensus on GLILD, providing a multidisciplinary view of the disease.

109. Chase NM, Verbsky JW, Hintermeyer MK, et al. Use of combination chemotherapy for treatment of granulomatous and lymphocytic interstitial lung disease (GLILD) in patients with common variable immunodeficiency (CVID). J Clin Immunol. 2013 Jan;33(1):30-39. PubMed PMID: 22930256; PubMed Central PMCID: PMCPMC3557581.

-. Two clinical studies providing relevant information (rationale and outcome) on the treatment of CVID-related ILD.

110. Morimoto Y, Routes JM. Granulomatous disease in common variable immunodeficiency. Curr Allergy Asthma Rep. 2005 Sep;;5 (5):370-375. PubMed PMID: 16091208.

111. Hartono S, Motosue MS, Khan S, et al. Predictors of granulomatous lymphocytic interstitial lung disease in common variable immunodeficiency. Ann Allergy Asthma Immunol. 2017 May;118 (5):614-620. PubMed PMID: 28254202.

112. Maglione PJ, Overbey JR, Cunningham-Rundles C. Progression of common variable immunodeficiency interstitial lung disease accompanies distinct pulmonary and laboratory findings. J Allergy Clin Immunol Pract. 2015 Nov-Dec;3(6):941-950. PubMed PMID: 26372540; PubMed Central PMCID: PMCPMC4641811.

113. Resnick ES, Moshier EL, Godbold JH, et al. Morbidity and mortality in common variable immune deficiency over 4 decades. Blood. 2012 Feb 16;119(7):1650-1657. PubMed PMID: 22180439; PubMed Central PMCID: PMCPMC3286343.

114. Gregersen S, Aalokken TM, Mynarek G, et al. Development of pulmonary abnormalities in patients with common variable immunodeficiency: associations with clinical and immunologic factors. Ann Allergy Asthma Immunol. 2010 Jun;104(6):503-510. PubMed PMID: 20568383.
115. Cereser L, Girometti R, d'Angelo $P$, et al. Humoral primary immunodeficiency diseases: clinical overview and chest high-resolution computed tomography (HRCT) features in the adult population. Clin Radiol. 2017 Jul;72(7):534-542. PubMed PMID: 28433201.

116. Jolles $S$, Carne E, Brouns $M$, et al. FDG PET-CT imaging of therapeutic response in granulomatous lymphocytic interstitial lung disease (GLILD) in common variable immunodeficiency (CVID). Clin Exp Immunol. 2017 Jan;187(1):138-145. PubMed PMID: 27896807; PubMed Central PMCID: PMCPMC5167039.

117. Bouvry D, Mouthon L, Brillet PY, et al. Granulomatosis-associated common variable immunodeficiency disorder: a case-control study versus sarcoidosis. Eur Respir J. 2013 Jan;41(1):115-122. PubMed PMID: 22903958.

118. Naccache JM, Bouvry D, Valeyre D. Bronchoalveolar lavage cytology resembles sarcoidosis in a subgroup of granulomatous CVID. Eur Respir J. 2014 Mar;43(3):924-925. PubMed PMID: 24585876.

119. Kollert F, Venhoff N, Goldacker S, et al. Bronchoalveolar lavage cytology resembles sarcoidosis in a subgroup of granulomatous CVID. Eur Respir J. 2014 Mar;43(3):922-924. PubMed PMID: 24585875.

120. Poletti V, Ravaglia C, Dubini A, et al. How might transbronchial cryobiopsy improve diagnosis and treatment of diffuse parenchymal lung disease patients? Expert Rev Respir Med. 2017 Dec;11 (12):913-917. PubMed PMID: 29050527.

121. Arish N, Eldor R, Fellig Y, et al. Lymphocytic interstitial pneumonia associated with common variable immunodeficiency resolved with intravenous immunoglobulins. Thorax. 2006 Dec;61(12):1096-1097. PubMed PMID: 17114373; PubMed Central PMCID: PMCPMC2117067.

122. de Gracia J, Vendrell M, Alvarez A, et al. Immunoglobulin therapy to control lung damage in patients with common variable immunodeficiency. Int Immunopharmacol. 2004 Jun;4(6):745-753. PubMed PMID: 15135316.

123. Boursiquot JN, Gerard L, Malphettes M, et al. Granulomatous disease in CVID: retrospective analysis of clinical characteristics and treatment efficacy in a cohort of 59 patients. J Clin Immunol. 2013 Jan;33(1):84-95. PubMed PMID: 22986767.

124. $\mathrm{Ng} \mathrm{J}$, Wright $\mathrm{K}$, Alvarez $\mathrm{M}$, et al. Rituximab monotherapy for common variable immune deficiency-associated granulomatous-lymphocytic interstitial lung disease. Chest. 2019 May;155(5):e117-e121. PubMed PMID: 31060706.

125. Maglione PJ, Gyimesi G, Cols M, et al. BAFF-driven B cell hyperplasia underlies lung disease in common variable immunodeficiency. JCI Insight. 2019 Mar 7;4(5): DOI:10.1172/jci.insight.122728 PubMed PMID: 30843876; PubMed Central PMCID: PMCPMC6483510.

- Two clinical studies providing relevant information (rationale and outcome) on the treatment of CVID-related ILD.

126. Pecoraro A, Crescenzi L, Galdiero MR, et al. Immunosuppressive therapy with rituximab in common variable immunodeficiency. Clin Mol Allergy. 2019;17:9. PubMed PMID: 31080365; PubMed Central PMCID: PMCPMC6501382

127. Bucciol G, Petrone A, Putti MC. Efficacy of mycophenolate on lung disease and autoimmunity in children with immunodeficiency. Pediatr Pulmonol. 2017 Oct;;52(10):E73-E76. PubMed PMID: 28672090.

128. Deya-Martinez A, Esteve-Sole A, Velez-Tirado N, et al. Sirolimus as an alternative treatment in patients with granulomatous-lymphocytic lung disease and humoral immunodeficiency with impaired regulatory T cells. Pediatr Allergy Immunol. 2018 Jun;29(4):425-432. PubMed PMID: 29532571.

129. Shamriz O, Shadur B, NaserEddin A, et al. Respiratory manifestations in LPS-responsive beige-like anchor (LRBA) protein-deficient patients. Eur J Pediatr. 2018 Aug;i177(8):1163-1172. PubMed PMID: 29777306.

130. Maccari ME, Abolhassani $H$, Aghamohammadi A, et al. Disease evolution and response to rapamycin in activated phosphoinositide 3-kinase delta syndrome: the european society for immunodeficiencies-activated phosphoinositide 3-kinase delta syndrome registry. Front Immunol. 2018;9:543. PubMed PMID: 29599784; PubMed Central PMCID: PMCPMC5863269.

131. Fattorossi A, Battaglia A, Buzzonetti $A$, et al. Circulating and thymic CD4 CD25 T regulatory cells in myasthenia gravis: effect of 
immunosuppressive treatment. Immunology. 2005 Sep;116 (1):134-141. PubMed PMID: 16108825; PubMed Central PMCID: PMCPMC1802400.

132. Catzola V, Battaglia A, Buzzonetti A, et al. Changes in regulatory T cells after rituximab in two patients with refractory myasthenia gravis. J Neurol. 2013 Aug;260(8):2163-2165. PubMed PMID: 23749295.

133. Cinetto F, Compagno N, Scarpa R, et al. Rituximab in refractory sarcoidosis: a single centre experience. Clin Mol Allergy. 2015;13 (1):19. PubMed PMID: 26330764; PubMed Central PMCID: PMCPMC4556310.

134. Sirajuddin A, Raparia K, Lewis VA, et al. Primary Pulmonary Lymphoid Lesions: radiologic and Pathologic Findings. Radiographics. 2016 Jan-Feb;36(1):53-70. PubMed PMID: 26761531.

135. Bierry G, Boileau J, Barnig C, et al. Thoracic manifestations of primary humoral immunodeficiency: a comprehensive review. Radiographics. 2009 Nov;29(7):1909-1920. PubMed PMID: 19926753.

136. Latour S, Winter S. Inherited Immunodeficiencies With High Predisposition to Epstein-Barr Virus-Driven Lymphoproliferative Diseases. Front Immunol. 2018;9:1103. PubMed PMID: 29942301; PubMed Central PMCID: PMCPMC6004768.

137. Reichenberger $F$, Wyser C, Gonon $M$, et al. Pulmonary mucosa-associated lymphoid tissue lymphoma in a patient with common variable immunodeficiency syndrome. Respiration. 2001;68(1):109-112. PubMed PMID: 11223743.

138. Malphettes M, Gerard L, Galicier L, et al. Good syndrome: an adult-onset immunodeficiency remarkable for its high incidence of invasive infections and autoimmune complications. Clin Infect Dis. 2015 Jul 15;61(2):e13-9. PubMed PMID: 25828999.

139. Vignesh P, Rawat A, An SS. Update on the use of immunomodulators in primary immunodeficiencies. Clin Rev Allergy Immunol. 2017 Apr;52(2):287-303. PubMed PMID: 27873163.

140. Italian Primary Immunodeficiency Network (IPINet). Recommendations on CVID management. https://www.aieop.org/web/operatori-sanitari/ gruppi-di-lavoro/immunodeficienze/

141. Serra G, Milito C, Mitrevski M, et al. Lung MRI as a possible alternative to $C T$ scan for patients with primary immune deficiencies and increased radiosensitivity. Chest. 2011 Dec;140(6):1581-1589. PubMed PMID: 21622550.

142. Milito C, Pulvirenti F, Serra G, et al. Lung magnetic resonance imaging with diffusion weighted imaging provides regional structural as well as functional information without radiation exposure in primary antibody deficiencies. J Immunol Clin. 2015 Jul;35 (5):491-500. PubMed PMID: 26067227; PubMed Central PMCID: PMCPMC4502290.

143. Jolles S, Orange JS, Gardulf A, et al. Current treatment options with immunoglobulin $\mathrm{G}$ for the individualization of care in patients with primary immunodeficiency disease. Clin Exp Immunol. 2015 Feb;179(2):146-160. PubMed PMID: 25384609; PubMed Central PMCID: PMCPMC4298393.

144. Romei C, Turturici L, Tavanti L, et al. The use of chest magnetic resonance imaging in interstitial lung disease: a systematic review. Eur Respir Rev. 2018 Dec 31;27(150). DOI:10.1183/16000617.00622018. PubMed PMID: 30567932.

145. Weatherley ND, Eaden JA, Stewart NJ, et al. Experimental and quantitative imaging techniques in interstitial lung disease. Thorax. 2019 Mar 18. DOI:10.1136/thoraxjnl-2018-211779. PubMed PMID: 30886067.

146. Langereis JD, van der Flier $M$, de Jonge MI. Limited innovations after more than 65 years of immunoglobulin replacement therapy: potential of IgA- and IgM-enriched formulations to prevent bacterial respiratory tract infections. Front Immunol. 2018;9:1925. PubMed PMID: 30190722; PubMed Central PMCID: PMCPMC6115500.

147. Corthesy B, Monnerat J, Lotscher M, et al. Oral passive immunization with plasma-derived polyreactive secretory-like $\lg \mathrm{A} / \mathrm{M}$ partially protects mice against experimental salmonellosis. Front Immunol. 2018;9:2970. PubMed PMID: 30619327; PubMed Central PMCID: PMCPMC6305475

148. Vonarburg C, Loetscher M, Spycher MO, et al. Topical application of nebulized human $\lg$, $\lg A$ and $\lg A M$ in the lungs of rats and non-human primates. Respir Res. 2019 May 22;20(1):99. PubMed PMID: 31118031.

149. Horn J, Thon V, Bartonkova D, et al. Anti-IgA antibodies in common variable immunodeficiency (CVID): diagnostic workup and therapeutic strategy. Clin Immunol. 2007 Feb;;122(2):156-162. PubMed PMID: 17137841.

150. Tsujita $Y$, Imai K, Honma K, et al. A severe anaphylactic reaction associated with IgM-class anti-human IgG antibodies in a hyper-IgM syndrome type 2 patient. J Clin Immunol. 2018 Jan;38 (1):144-148. PubMed PMID: 29255996. 